\title{
Pharmacokinetics, Bio Distribution and Therapeutic Applications of Recently-Developed siRNA and DNA Repair Genes Recurrence
}

\author{
Madkour LH* \\ Chemistry Department, Faculty of Science Tanta \\ University, 31527, Tanta, Egypt \\ *Corresponding author: Loutfy H Madkour, \\ Chemistry Department, Faculty of Science Tanta \\ University, 31527, Tanta, Egypt
}

Received: September 20, 2021; Accepted: October 22, 2021; Published: October 29, 2021

\begin{abstract}
Up regulation of cell cycle-regulating and DNA repair genes appears to have a negative impact on recurrence-free survival in patients with papillary thyroid cancer. Furthermore, recurrence is associated with thyroid dedifferentiation.

Most cases address local applications or diseases in the filtering organs, reflecting remaining challenges in systemic delivery of siRNA. Small Interfering RNA (siRNA) is a promising drug candidate, expected to have broad therapeutic potentials toward various diseases including viral infections and cancer. With recent advances in bio conjugate chemistry and carrier technology, several siRNA-based drugs have advanced to clinical trials. The difficulty in siRNA delivery is in large part due to poor circulation stability and unfavorable pharmacokinetics and bio distribution profiles of siRNA.
\end{abstract}

In this research we describe the pharmacokinetics and bio distribution of siRNA Nano medicines, focusing on those reported in the past 5 years, and their pharmacological effects in selected disease models such as hepatocellular carcinoma, liver infections, and respiratory diseases. The examples discussed here will provide an insight into the current status of the art and unmet needs in SiRNA delivery.

Keywords: RNA interference; Small interfering RNA; Delivery; Pharmacokinetics; Biodistribution; Cancer

\section{Introduction}

\section{RNAi as a potential therapeutic}

RNA interference (RNAi) is an endogenous post-transcriptional regulation process, which involves small regulatory RNAs such as Small Interfering RNAs (siRNAs) or MicroRNAs (miRNAs) that silence target messenger RNAs in a sequence-specific manner. Ever since the discovery of RNAi in Caenorhabditis elegans [1] and the demonstration of siRNA activity in mammalian cells [2], RNAi has gained significant attention as a potential therapeutic for various diseases including viral infections and cancer, especially for those lacking 'druggable' targets. The efforts to develop siRNA therapeutics resulted in the first trial in human [3] in less than a decade since the discovery. However, realizing the clinical potential of siRNA therapeutics has found to be a daunting task, in large part due to the unfavorable Pharmacokinetics (PK) and Biodistribution (BD) profiles of systemically administered siRNA [4-6]. This challenge has been tackled in various ways, including chemical modification of siRNAs and/or the use of Nano particulate delivery systems based on lipids, polymers, and inorganic platforms, which aim to protect the siRNAs from serum proteins and renal clearance and help cross target cell membranes. These approaches have improved the bioavailability of siRNA and enabled at least 30 siRNA-based drugs to enter clinical trials [7]. Nevertheless, 70\% of them address ocular diseases, where siRNA is administered locally, or target the liver, lung, or kidney, the filtering organs in which the formulations are naturally captured, indicating that the systemic delivery of RNAi therapeutics to other organs remains a critical challenge. To overcome this challenge and translate the broad potential of RNAi therapeutics to clinical benefits, it is important to understand the level of PK and BD control achieved by current delivery approaches. The purpose of this chapter is to provide an overview of the current status of the art in siRNA delivery with respect to the effects of carriers on $\mathrm{PK}, \mathrm{BD}$, and pharmacological effects of systemically administered siRNA. Due to the large volume of literature, we mainly discuss the studies published in the past 5 years.

\section{Methods}

\section{Therapeutic applications of siRNA and target genes}

Ocular disease: RNAi has been found to be effective in the treatment of ocular diseases [8]. In early studies, local injection of siRNA targeting Vascular Endothelial Growth Factor (VEGF) was shown to reduce neovascularization in several animal models of eye injuries, such as laser-induced photocoagulation [9], suture-induced corneal angiogenesis [10], and CpG oligodeoxynucleotide- or herpes simplex virus-induced neovascularization [11]. Neovascularization is a critical pathological event in age-related macular degeneration (AMD) [12] and diabetic retinopathy [13,14]. Therefore, siRNAs suppressing the expression of VEGF, receptors, and/or its regulation have been explored as a potential therapy and tested in human for the treatment of AMD (Bevasiranib silencing VEGF) [15] and diabetic macular edema (PF-04523655 silencing hypoxia inducible gene) [16]. 
Fibrotic eye diseases are significant complications of eye surgeries. Transforming growth factor $\beta$ (TGF- $\beta$ ) is identified as a main culprit of postoperative ocular scarring; thus, siRNA targeting TGF- $\beta$ or its receptor is used to inhibit fibrotic responses to wounding. For example, siRNA targeting type II receptor of TGF- $\beta$ was shown to reduce inflammatory responses and collagen deposition in a mousemodel of subconjunctival inflammation and fibrosis [17]. Similarly, siRNAmediated downregulation of I $\mathrm{B} B$ kinase beta $(\mathrm{IKK} \beta)$, an activator of NF- $\mathrm{KB}$-mediated inflammation and cell proliferation, reduced subconjunctival scarring in a monkey model of glaucoma filtration surgery [18]. siRNA is also pursued for glaucoma therapy. siRNA targeting $\beta 2$-adrenoceptors (SYL040012) was shown to reduce the expression of $\beta 2$ adrenergic receptor and the production of aqueous humor, thereby reducing intraocular pressure [19].

Based on promising preclinical results, several siRNA therapeutics entered clinical trials for ocular disease therapy $[8,20]$. Due to the accessibility and the blood ocular barrier, most siRNAs targeting ocular diseases are administered via local routes, such as intravitreal injection, sub conjunctival injection, or topical instillation $[8,20]$. Therefore, ocular application of siRNA will not be covered in the following PK/BD discussion.

\section{Results and Discussion}

\section{Cancer}

Due to the high selectivity and specificity, siRNA has been widely explored as a new therapeutic agent to replace or supplement traditional cytotoxic chemotherapy [21-23]. Targets often considered for siRNA- based cancer therapy include genes promoting uninhibited cell growth, such as VEGFs [24], c-myc [25], EphA2[26], Raf-1[27], polo-like kinase 1 (Plk1) [28], Cyclin-Dependent Kinases (CDKs) [29], and those helping cancer cells survive or resist chemotherapy such as survivin and Multidrug Resistance (MDR) genes [30] (Table $1)$.

VEGF and corresponding receptors (VEGFRs) participate in the regulation of blood vessel development during early embryogenesis [41]. Binding of VEGF to VEGFR activates multiple cellular pathways important for angiogenesis, an essential component of tumor growth and metastasis. Therefore, siRNAs targeting VEGF/VEGFR are explored as potential anti-cancer therapeutics. C-myc is an oncogene overexpressed in various human tumors, which promotes cell growth, transformation, and angiogenesis [25]. In particular, c-myc expression in melanoma is indispensable for nucleotide metabolism and proliferation of tumor cells [42]. Downregulation of c-myc inhibits tumor growth and sensitizes cancer cells to chemotherapy, possibly by induction of $\mathrm{p} 53$ and inhibition of $\mathrm{Bcl}-2$ proteins, which trigger cell apoptosis [43].

EphA2 is a well-known receptor tyrosine kinase belonging to the Eph family, overexpressed in many cancers including breast cancers and ovarian cancers, implicated in poor clinical outcomes [44]. Contact dependent cell-cell interactions controlled by Eph receptors and ephrin (ligand of Eph receptors) signaling are tightly regulated in normal embryonic development and maintenance of homeostasis [45]. During oncogenes is, normal EphA2-EphrinA1 signaling is disrupted due to the loss of cell contacts, leading to overexpression of EphA2 and oncogenic signal transduction [45]. This dysregulated signaling is implicated in several critical aspects of oncogenes is such as cytoskeleton modulation, cell adhesion, migration, metastasis, proliferation and angiogenesis [45]. Plk1, a serine/threonineprotein kinase, is responsible for cell mitosis in mammalian cells. It is overexpressed in various human cancers as a proto-oncogene, which inactivates tumor suppressor proteins like p53 [46,47]. CDKs are also serine/threonine kinases and essential for the regulation of the cell cycle progression [48]. The abnormal expression or activity of distinct CDK complexes causes cells to escape from a well-controlled cell cycle, resulting in malignant transformation [49-51]. Palbociclib, an inhibitor of CDK4/6, received Breakthrough Therapy designation from the FDA in April 2013, for the initial treatment of patients with breast cancer [52].

Survivin is an inhibitor of programmed cell death (apoptosis), expressed in various types of malignant tumor cells, especially in drug resistant cells [53]. Survivin was initially identified as an inhibitor of caspase- 9 and also found to be involved in the regulation of the mitotic spindle checkpoint and the promotion of angiogenesis and chemo resistance [54]. Therefore, siRNA targeting Survivin is pursued as a way of potentiating the activity of chemotherapeutics. Another main cause of failure in chemotherapy is Multi-Drug Resistance (MDR) related P-Glycoprotein (Pgp). Pgp, a typical ATP-binding cassette membrane transporter, causes efflux of a broad range of drugs from a cell, reducing effective accumulation of the drugs in the cell [55]. Overexpression of Pgp, also known as MDR 1 protein 1 (MDR-1), and up-regulation of its functional activity in cancer cells lead to reduced sensitivity to chemotherapy, thus making an attractive target

Table 1: Target genes for siRNA therapeutics in cancer.

\begin{tabular}{|c|c|c|}
\hline Target genes & Function of target genes & Diseases \\
\hline VEGF & Angiogenesis & Lung cancer and metastasis \\
\hline VEGFR & Angiogenesis & Lung adenocarcinoma \\
\hline c-myc & Cell proliferation & Melanoma cancer \\
\hline c-myc, MDM2, VEGF & Cell proliferation; p53 inhibition; angiogenesis & Melanoma cancer \\
\hline EphA2 & Cell-cell interactions & Ovarian cancer \\
\hline Raf-1 & RAS/MAPK signaling pathway & Melanoma cancer \\
\hline PLK1 & Cell division & Renal cell carcinoma \\
\hline CDK1 & [35] & Breast cancer \\
\hline Survivin & Cell cycle progression & [37] \\
\hline MDR-1 & Drug resistance & Drug resistant lung cancer and cervical cancer \\
\hline
\end{tabular}


Table 2: Target genes for siRNA therapeutics in hepatocellular carcinoma.

\begin{tabular}{|c|c|c|}
\hline Target genes & Function of target genes \\
\hline VEGF & Tumor angiogenesis and pathogenesis \\
\hline EGFR & Cell survival, proliferation, and differentiation \\
\hline NIK & Cell proliferation \\
\hline ApoB & [65] \\
\hline Notch-1 & Formation of LDL, metabolism of dietary and endogenous cholesterol \\
\hline [71]
\end{tabular}

Table 3: Target genes for siRNA therapeutics in hepatic viral infections.

\begin{tabular}{|c|c|c|c|}
\hline Target genes & Function of target genes & Diseases & References \\
\hline $\mathrm{HBx}$ & Regulates HBV transcription and translation & HBV & {$[78,93]$} \\
\hline Core & Regulates viral DNA replication & HBV & {$[81,82]$} \\
\hline IRES in 5'-UTR & Facilitates RNA translation & $\mathrm{HCV}$ & [86-88] \\
\hline Core & Triggers activation of multiple signaling pathways in HCV & $\mathrm{HCV}$ & [89] \\
\hline E1, E2 & Viral attachment to cells & $\mathrm{HCV}$ & {$[90]$} \\
\hline $\begin{array}{l}\text { L protein, VP24 } \\
\text { and VP35 }\end{array}$ & $\begin{array}{l}\text { L protein: RNA polymerase activity; } \\
\text { VP24/VP35: inhibitory effects on host } \\
\text { type } 1 \text { interferon response }\end{array}$ & $\begin{array}{c}\text { Ebola } \\
\text { virus }\end{array}$ & [91] \\
\hline
\end{tabular}

for siRNA therapy [56].

\section{Liver diseases}

As a filtering organ where most Nano particulate delivery systems are naturally captured, the liver has been the main target for most siRNA therapeutics currently in clinical evaluation stages [57]. Target diseases include Hepatocellular Carcinoma (HCC), viral hepatitis, liver fibrosis, and hypercholesterolemia [58].

HCC: HCC occurs by cumulative generic mutations, which lead to the dysfunctional regulation of cellular machinery and proliferation [59]. RNAi therapy has been pursued to modulate the mutated genes involved in the oncogenesis of HCC, such as Adenomatous Polyposis Coli (APC), VEGF-A, Fibroblast Growth Factor Substrate 2 (FRS2), and Phosphoinositide 3-Kinase (PIK3) [60-63] (Table 2). These genes play an essential role in signal transduction pathways in HCC pathogenesis, including Wnt/ $\beta$-catenin, VEGF, FGF, and PI3K/AKT/ mTOR pathways [64-67]. For example, HCC is a highly vascularized tumor, where proangiogenic factors like VEGF-A, the major VEGF responsible for tumor angiogenesis and pathogenesis, are frequently over-expressed [65]. Therefore, several studies explored siRNA targeting the VEGF pathway for HCC therapy. The Epidermal Growth Factor Receptor (EGFR) signaling pathway is another important target [68], with its overexpression detected in $40-70 \%$ of the tumors in pre-neoplastic HCC [69].

In addition to siRNAs, several miRNAs have been identified as a potential therapy of HCC. For example, miR-122, a liver-specific tumor suppressor miRNA frequently down-regulated in HCC, has drawn increasing attention over the years [70]. Due to the similarity in structure, miRNAs are delivered in similar ways as siRNAs.

Hepatic viral infections (Table 3): Hepatitis virus infection accounts for most cases of liver infections. When left untreated, patients infected by hepatitis B, C, and D viruses are chronically disturbed and further develop liver cirrhosis and HCC [74]. Currently, 90\% hepatitis B vaccine is effective in preventing Hepatitis B Virus (HBV) infection, but $>700,000$ deaths still occur worldwide as a consequence of HBV infection [75]. Patients with chronic HBV infection are currently treated with antiviral agents such as tenofovir and entecavir together with immunomodulators like IFN- $\alpha 2 b$, but side effects and viral resistance limit the effectiveness of these therapies [76]. In this regard, RNAi is considered a potentially attractive treatment for $\mathrm{HBV}$ infection. Hepatitis B virion is composed of circular double stranded DNA, which contains four overlapping open reading frames (ORFs: $\mathrm{S}, \mathrm{Pol}, \mathrm{X}$ and $\mathrm{C}$ ) that encode essential proteins like pre-core protein (also known as $\mathrm{HBeAg}$ ), core protein $(\mathrm{HBcAg})$, envelope protein (HBsAg), X protein and viral polymerase [77]. Among them, the X protein, encoded by ORF X gene, was known to regulate transcription and translation by transactivation of viral and cellular promoters, and several studies showed that $\mathrm{HBX}$-specific siRNAs could suppress HBV viral replication $[78,79]$. ORF $\mathrm{C}$ is another valid target. It encodes polyadenylation region that plays important function in all the transcripts [80] and contains sequences that can encode Nuclear Localization Signal (NLS) needed for transporting Covalently Closed Circular DNA (cccDNA), which serves as the template for viral transcription $[81,82]$.

Hepatitis C Virus (HCV) comprises seven different genotypes with more than 50 subtypes and billions of quasi-species [83]. Current treatment by PEGylated interferons and nucleoside inhibitors like ribavirin is effective in $70-80 \%$ of patients with genotype 2 or 3 but less effective in patients with other genotypes [84]. Side effects are also common among patients receiving this combination treatment [84]. $\mathrm{HCV}$ genome sequences are highly variable as compared to HBV, but $5^{\prime}$-untranslated region (5'-UTR) contains conserved Internal Ribosome Entering Site (IRES), essential for virus replication, providing a useful target for RNAi therapy [85-88]. Moreover, siRNAs targeting HCV-core gene [89] or E1, E2 [90] resulted in dramatic reduction in virus RNA by interfering with multiple signaling pathways in $\mathrm{HCV}$ or inhibiting the viral attachment to the cells. In addition to hepatitis virus infections, the liver is also one of the primary sites for Ebola virus replication, and RNAi has been pursued as a potential treatment $[91,92]$.

Respiratory diseases: RNAi as a potential treatment of respiratory diseases has been reviewed extensively in recent literature 
Table 4: Target genes for siRNA therapeutics in respiratory diseases.

\begin{tabular}{|c|c|c|c|}
\hline Target genes & Function of target genes & Disease & References \\
\hline Ga12 \& Ga13 & Promotes the growth and oncogenic transformation & Small cell lung cancer & [96] \\
\hline Wilms' tumor gene (WT1) & Encodes a transcription factor involved in gonadal development & Melanoma lung metastasis & [97] \\
\hline $\begin{array}{l}\text { Nucleocapsid protein (NP) } \\
\text { gene }\end{array}$ & Produces nucleocapsid proteins & Influenza infection & {$[98,99]$} \\
\hline P protein & $\begin{array}{l}\text { Essential for RNA-dependent RNA polymerase (RdRP) holoenzyme to exit the } \\
\text { promoter and to form a closed complex capable of sustained elongation }\end{array}$ & $\begin{array}{l}\text { Respiratory syncytial virus and } \\
\text { parainfluenza virus }\end{array}$ & [100] \\
\hline $\begin{array}{l}\text { Epithelial sodium channel } \\
\text { (ENaC) }\end{array}$ & $\begin{array}{c}\text { Stimulates sodium and water absorption, counteracting cystic fibrosis } \\
\text { transmembrane regulator (CFTR) activity }\end{array}$ & Cystic fibrosis & [101] \\
\hline Interleukin-4 (IL-4) & $\begin{array}{l}\text { Promotes the differentiation and proliferation of Th2 cells and facilitates the antibody } \\
\text { class switching of B cells to IgE }\end{array}$ & $\begin{array}{l}\text { Asthma-associated inflammatory } \\
\text { reactions }\end{array}$ & [102] \\
\hline IL-13 & $\begin{array}{l}\text { Induces vascular cell adhesion molecule-1 and chemokines (e.g. eotaxin, MIP-1a) to } \\
\text { recruit and activates inflammatory cells; directly affects airway smooth muscle }\end{array}$ & $\begin{array}{l}\text { Airway resistance in allergen } \\
\text { exposure }\end{array}$ & [103] \\
\hline
\end{tabular}

[94,95]. A number of studies have demonstrated the use of siRNAs for the treatment of lung cancer, viral infection, cystic fibrosis, and inflammatory lung diseases (Table 4). Knockdown of G proteins (Ga12 and Ga13) was shown to abolish H69 tumorigenicity in mice for the treatment of Small Cell Lung Cancer (SCLC) [96]. Silencing of the Wilms' Tumor gene (WT1) was shown to be effective in treating melanoma lung metastases [97]. Administration of siRNAs targeting the conserved regions of influenza virus genes or nucleocapsid protein gene resulted in prevention and treatment of influenza infection $[98,99]$. The effectiveness of siRNA was also demonstrated in Respiratory Syncytial Virus (RSV) and Parainfluenza Virus (PIV) infections [100]. siRNA therapeutics have been pursued for the therapy of cystic fibrosis, a genetic disorder that fatally affects the lung functions. Epithelial Sodium Channel (ENaC) was identified as a potential target for RNAi therapy of cystic fibrosis [101]. For asthmaassociated inflammatory reactions, the knockdown of IL-4 alleviated airway inflammations [102], and siRNA targeting IL-13 reduced airway resistance in allergen-challenged mice [103].

\section{Pharmacokinetics of siRNA therapeutics}

Preclinical studies: For systemic delivery of siRNA, it is critical to maintain siRNA stable with a long half-life $\left(t_{1 / 2}\right)$ in circulation. To investigate the effect of carriers on the circulation $t_{1 / 2}$ of siRNA, the siRNA is often labeled with radioactive elements or fluorescent dyes, and the radioactivity or fluorescence intensity of blood is measured at regular time points. siRNA complexed with Nanoparticles (NPs) typically shows a longer $t_{1 / 2}$ (the time required to reduce the plasma concentration of a drug to one half of its initial value), higher Area Under The Curve (AUC) (the overall amount of a drug in the bloodstream after a dose), lower plasma Clearance $(\mathrm{Cl})$ (the volume of plasma in the vascular compartment cleared of a drug per unit time), and longer Mean Retention Time (MRT) (the average time a drug molecule stays in the body) than free (naked) siRNA, provided that the complex remains stable in circulation.

Xia et al. used Magnetic Mesoporous SilicaNPs (M-MSN) as a carrier of siRNA [31]. Here, siRNA was loaded in mesopores of the carrier, which was capped with polyethyleneimine (PEI) and surfacemodified with Polyethylene Glycol (PEG) and a fusogenic peptide. Fluorescence Dye (Cy3) was conjugated to the $5^{\prime}$ end of the sense strand for detection of siRNA in blood. The blood level of free Cy3siRNA was reduced to $1 \%$ of the Injected Dose per Gram (ID/g) of blood within $20 \mathrm{~min}$. In contrast, Cy3-siRNA loaded in M-MSN maintained $\sim 5 \%$ of the injected dose per gram of blood in the first hour [31]. This difference translated to significantly increased

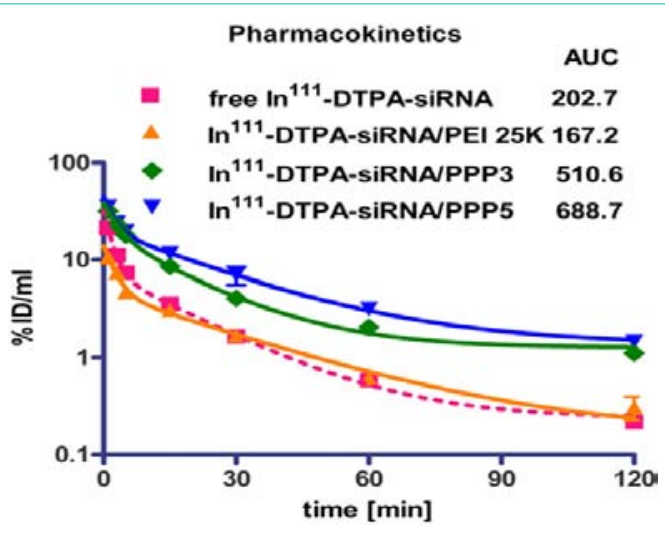

Figure 1: PK of siRNA polyp lexes and free siRNA as measured by gamma scintillation counting of blood samples. PPP indicates PEI-g-(PCL-b-PEG); 3 and 5 indicate graft density of PCLPEG to PEI [104].

bioavailability of siRNA. Free Cy3-siRNA showed an AUC of 40.13 $\pm 30.49 \mathrm{~min} \mathrm{mg} / \mathrm{mL}$, a plasma Cl of $57.96 \pm 58.07 \mathrm{~mL} / \mathrm{min} / \mathrm{kg}$, and a MRT of $70.67 \pm 20.39 \mathrm{~min}$, whereas Cy3-siRNA packaged in M-MSN showed AUC, $\mathrm{Cl}$, and MRT of $573.34 \pm 145.12 \mathrm{~min} \mathrm{mg} / \mathrm{mL}, 2.41 \pm$ $0.51 \mathrm{~mL} / \mathrm{min} / \mathrm{kg}$, and $310.15 \pm 21.68 \mathrm{~min}$, respectively [31]

As with other Nano medicine, surface modification of carriers with PEG helps extend the $t_{1 / 2}$ and increase the AUC. Kissel et al. developed amphiphilic biodegradable non-viral polymeric siRNA carrier, based on PEI, Polycaprolactone (PCL), and PEG [104]. To study PK of siRNA

Complexed with the polymer, they used ${ }^{111}$ In-radiolabeled siRNA and measured the radioactivity of the blood samples over time. Upon Intravenous (IV) injection, siRNA/PEI-g-PCL-b-PEG complexes showed longer circulation times, less steep $\alpha$ and $\beta$ elimination phases, and higher AUC values as compared to free siRNA or siRNA/ PEI complexes (Figure 1) [104].

On the other hand, siRNA/PEI complex showed a similar PK as free siRNA due to the instability of the complex (i.e., early dissociation of the complex in blood). Similarly, Harashima et al. compared PK parameters of a liposomal siRNA carrier, called a Multifunctional Envelope-Type Nanodevice (MEND), with and without PEGylation, and confirmed the significance of PEG modification [37]. siRNA and lipid envelope were labeled with radioisotopes, 32P and $3 \mathrm{H}$, respectively, and traced in normal mice after IV injection. The siRNA encapsulated in the MEND was eliminated from the bloodstream as rapidly as free siRNA, suggesting rapid clearance via the Mononuclear 

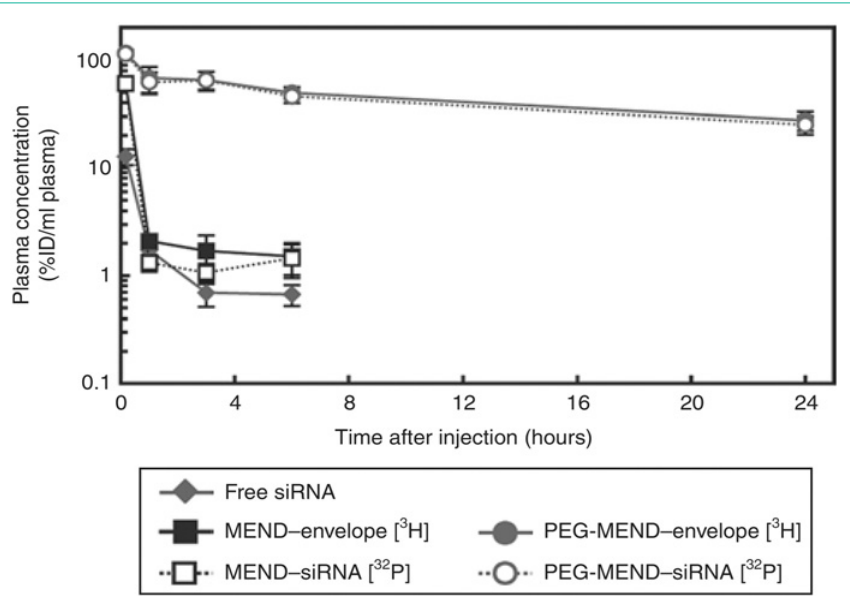

Figure 2: Blood concentration profile of systemically injected MENDs. The lipid envelope and siRNA were labeled with RIs $3 \mathrm{H}$ and $32 \mathrm{P}$, respectively. MENDs and free siRNA were injected via the tail vein of ICR mice, and then at $0.17,1,3,6$, and $24 \mathrm{~h}$ after injection, the radioactivity in plasma was measured by liquid scintillation counting. The data are represented as the mean \pm SD $(n=3)$. MEND, multifunctional envelope-type Nano device; RI: Radio Isotope [37]

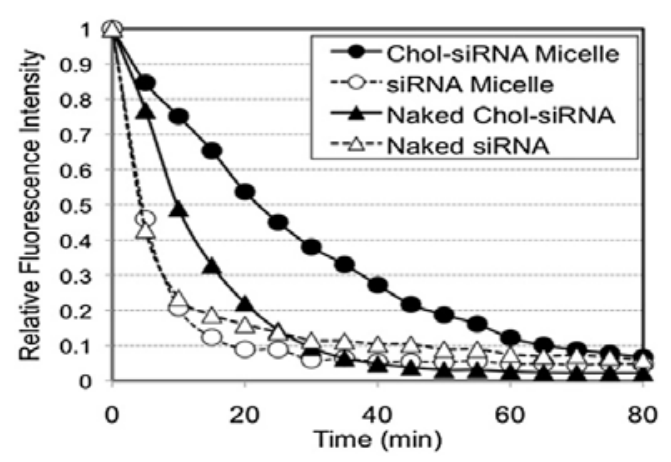

Figure 3: In vivo performance of siRNA encapsulated in PEG-PLL (MPA) micelles. Blood circulation profiles, determined by IVRT-CLSM after intravenous injection ( $3.6 \mathrm{nmol}$ siRNA/mouse) into BALB/c nude mice (open triangle: naked Chol-free/Cy5-siRNA, closed triangle: naked Chol/Cy5siRNA, open circle: Chol-free/Cy5-siRNA micelles and closed circle: Chol/ Cy5-siRNA micelles). Data represent the average value $(n=3)$ [105].

Phagocyte System (MPS) (Figure 2). On the other hand, siRNA formulated in the PEGMEND showed a longer $\mathrm{t}_{1 / 2 \beta}(16.9 \mathrm{~h}$ vs. $1.35 \mathrm{~h}$ of free siRNA) and higher AUC ( $344 \mu \mathrm{g} \mathrm{h} v 2.1 \mu \mathrm{g}$ of free siRNA). The ${ }^{3} \mathrm{H}$-labeled lipid component showed a similar blood concentration profile as ${ }^{32} \mathrm{P}$-labeled siRNA, suggesting that the complex was stable during circulation.

Another approach to increase the stability of siRNA/carrier complex involves covalent crosslinking of the carrier and introduction of hydrophobic interactions [105]. Kataoka et al. developed a polyion complex micelle system based on Cholesterol-Conjugated siRNA (chol-siRNA) and PEG-poly(L-lysine) block-co-polymer (PEGPLL) Modified with 1-(3-mercaptopropyl)Amidine (MPA),where the micelles were stabilized by disulfide cross-linking of the polymer and hydrophobic association of cholesterol groups [105]. siRNA was fluorescently labeled by conjugating Cy 5 dye to 5 ' end of the antisense strand, and the blood level of siRNA was measured by Intravital RealTime Confocal Laser Scanning Imaging (IVRT-CLSM) [105,106].
Unmodified siRNA (chol-free siRNA) loaded in PEG-PLL(MPA) micelles were rapidly eliminated from circulation, similar to naked siRNA, with a blood $t_{1 / 2}$ less than $5 \mathrm{~min}$, indicating that disulfide crosslinking of polymer alone did not stabilize the siRNA/micelle complexes. In contrast, micelles containing chol-siRNA showed a $t_{1 / 2}$ longer than $20 \mathrm{~min}$, which indicated the contribution of cholesterol to the stability of the complex (Figure 3) [105].

One caveat of using labeled siRNA in PK studies is that the labeled siRNA can be catabolized and misrepresent siRNA. Moreover, the labeling can cause structural modification in siRNA and change its $\mathrm{PK}$ and $\mathrm{BD}$. For example, siRNA labeled with ${ }^{111} \mathrm{In}$ via conjugation to $3^{\prime}$ end [107] and siRNA labeled with $3 \mathrm{H}$ through internal substitution [108] showed different PK and BD profiles. The former showed predominantly high distribution in the kidney and low distribution in the liver compared to other organs, but the latter showed high distribution in the salivary gland, spleen, and liver, in addition to the kidney $1 \mathrm{~h}$ after administration $[107,108]$.

To overcome such challenges, the amount of siRNA circulating or accumulating in tissues of interest has been determined by other analytical means such as Northern blotting [109], mass spectrometry, and qRT-PCR [37], which can selectively detect full-length siRNA. Swart et al. compared PK profiles of ${ }^{3} \mathrm{H}$-labeled siRNA with [110] and without a Lipid Nanoparticle (LNP) vehicle [108] after IV injection. Both free siRNA and LNP-complexed siRNA showed amultiexponential decrease in the concentration of total radiolabeled components with, however, vastly different elimination half-lives: 10 min for free siRNA and $162 \mathrm{~h}$ for siRNA/LNP complex $[108,110]$. Mass spectrometric profiling of metabolites in plasma, urine, and tissues found that free siRNAs were rapidly metabolized and distributed to tissues as low molecular weight metabolites [108]. In contrast, when injected as a siRNA/LNP complex, the guide strand of $3 \mathrm{H}$-siRNA was detectable in plasma up to $48 \mathrm{~h}$ and $168 \mathrm{~h}$ post-dose, as measured by LC-MS-Radioactivity (RA) and RTqPCR, respectively, with a Cmax of $1.04 \mu \mathrm{M}$ (LC-MS-RA) or $2.56 \mu \mathrm{M}$ (RT-qPCR) after $1 \mathrm{~h}$ [110]. LCMS-RA analysis found siRNA degradation products (14-18 mers) as the predominant component of total radioactivity in plasma but did not detect complete degradation products, which indicates the LNP formulation protected siRNA from metabolism at least partly [110].

Clinical studies: QPI-1002 was the first siRNA therapeutic systemically delivered to human [111]. QPI-1002 was a siRNA targeting proapoptotic protein $\mathrm{p} 53$, developed for the prevention of delayed graft function in patients receiving kidney transplantation. Since the target organ (kidney) was the natural destination of siRNA, it was administered as free siRNA without a carrier [111]. QPI-1002 completed Phase II trials in 2014, but its PK results are not available.

Clinical PK data for siRNA-lipid complex have been reported recently. ALN-VSP was LNPs (also known as SNALPs, stable nucleic acid-lipid particles) containing VEGF-A and Kinesin Spindle Protein (KSP) siRNAs, with a size of 80 to $100 \mathrm{~nm}$ and a near neutral zeta potential, developed for the treatment of advanced cancer and liver metastases [112]. ALNVSP was administered as 15-min IV infusion, and blood levels of total and unencapsulated siRNA were determined by the hybridization ELISA method and analyzed by non-compartmental method. The $\mathrm{C}_{\max }$ and AUC were similar for both siRNAs and dose-dependent. Most siRNA circulated as LNP 


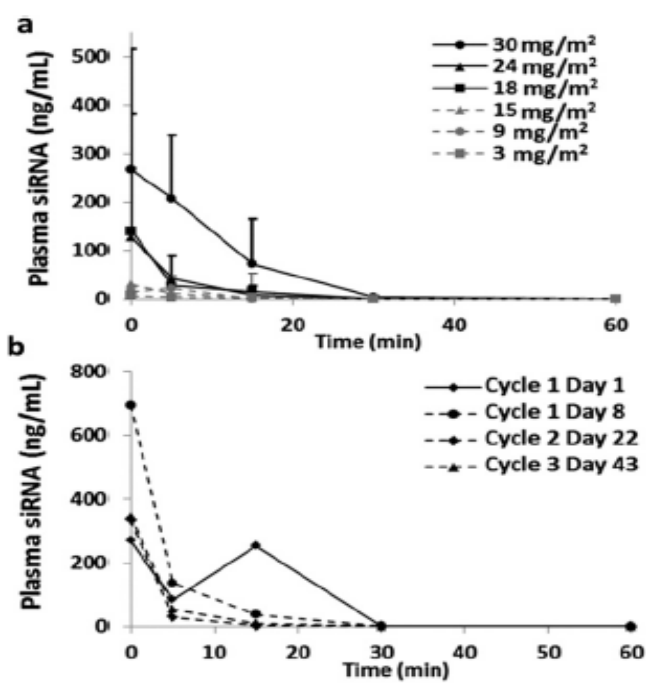

Figure 4: PK assessment of CALAA-01 in patients. (a) Time course of average plasma concentration of the siRNA component of CALAA-01 following the end of infusion for all dosing cohorts. (b) Time course of plasma CALAA-01 siRNA following the end of infusion from cycles 1-3 of CALAA-01 from one patient who received $30 \mathrm{mg} / \mathrm{m}^{2}$ CALAA-01. Lines connecting data points are guides for the eye only [115]

according to the comparison between total and free siRNA, and the level declined to a plateau in 6-7 h [112]. Another lipid-based siRNA tested in human was Atu027, a siRNA targeting protein kinase N3 (PKN3) carried by cationic LNPs, developed for the therapy of primary tumors and metastases [113]. Atu 027 was given as IV infusion for $4 \mathrm{~h}$ and analyzed with ELISA detecting single strand RNA. The blood level increased during the infusion period and declined after the end of infusion. The siRNA level declined more rapidly than lipid components, which suggests potential dissociation of the complex during circulation.

CALAA-01 was the first polymer-based siRNA therapeutic tested in human for cancer therapy [22]. CALAA-01 consisted of two components: siRNA designed to reduce the expression of the M2 subunit of ribonucleotide reductase (RRM2), a well-established target for cancer therapy, and the carrier component made of cationic Cyclodextrin-Based Polymer (CDP), PEG modified with a terminal Adamantane Group (ADPEG), and AD-PEG conjugated to human transferrin (AD-PEG-Tf). NPs targeted to transferrin receptors were produced by mixing siRNA and $\mathrm{CDP}$, to which the $\mathrm{AD}$-conjugated polymers were attached via inclusion complex formation [114]. PK studies from Phase I clinical trials with 24 patients were recently reported and comparedwith data obtained from multispecies animal studies [115]. siRNA in plasmawas analyzed by the hybridizationligation assay, which detected the oligonucleotide via hybridization of complementary template and ligation of signaling probe to the template [116]. The plasma concentrations of siRNA component of CALAA-1 rapidly declined to below the detection limit by 30 min after the end of infusion in most patients, with no apparent accumulation upon multiple dosing (Figure 4) [115]. There was a good correlation between AUC and $\mathrm{C}_{\max }$ of siRNA, which increased linearly with the dose (in $\mathrm{mg} / \mathrm{kg}$ ) [115]. Similar trends were observed in preclinical studies with different animal species including mice, rats, dogs, and monkeys. It is worthwhile to note that CALAA-1 was cleared through the kidney [117], unlike other NP-based therapeutics that undergo accumulation in the MPS. The authors attributed it to disassembly of siRNA/polymer complex at the kidney glomerular basement membrane but excluded the possibility of disassembly in circulation due to the stability demonstrated in the gel mobility shift assay [117].

\section{Biodistribution of siRNA therapeutics}

Similar to PK studies, siRNA BD is studied by tracking surrogate signals of fluorescent dyes or radioactive elements incorporated in siRNA or siRNA itself via PCR. Less frequently, NP carriers are tracked in lieu of siRNA under an assumption that the NPs represent the siRNA BD. Many BD studies are performed in animal models with solid xenograft tumors. siRNA stably encapsulated in NPs show increased tumor accumulation as compared to naked siRNA to some extent, due to the increased circulation t1/2 and the Enhanced Permeability and Retention (EPR) effect common in solid tumors. However, the majority of the injected dose ends up in organs where the MPS is located, including the spleen, liver and lung.

Tracking siRNA labeled with fluorescent dyes: Huang et al. used a Liposome-Polycation-Hyaluronic acid (LPH) NP system decorated with GC4-Single Chain Variable Fragment ( $\mathrm{scFv}$ ) for systemic delivery of a combination of siRNAs [34]. FITC-labeled siRNA was first complexed with protamine in the presence of Hyaluronic Acid (HA), combined with cationic liposomes, and injected IV to mice bearing experimental lung metastasis. At $4 \mathrm{~h}$ after IV injection, major organs were collected and lysed to yield supernatants; ofwhich fluorescence intensity was determined to represent the level of siRNA. With free siRNAs, most fluorescence signals were seen in the liver. siRNA carried by LPH NPs showed similar BD as free siRNA, except for 3 times stronger intensity in tumors [34]. This group used a similar NP system based on a Liposome-Polycation-DNA (LPD) with PEGylated Asn-Gly-Arg peptide (PEG-NGR) as a targeting ligand for the delivery of doxorubicin and siRNA combination [118]. At 4
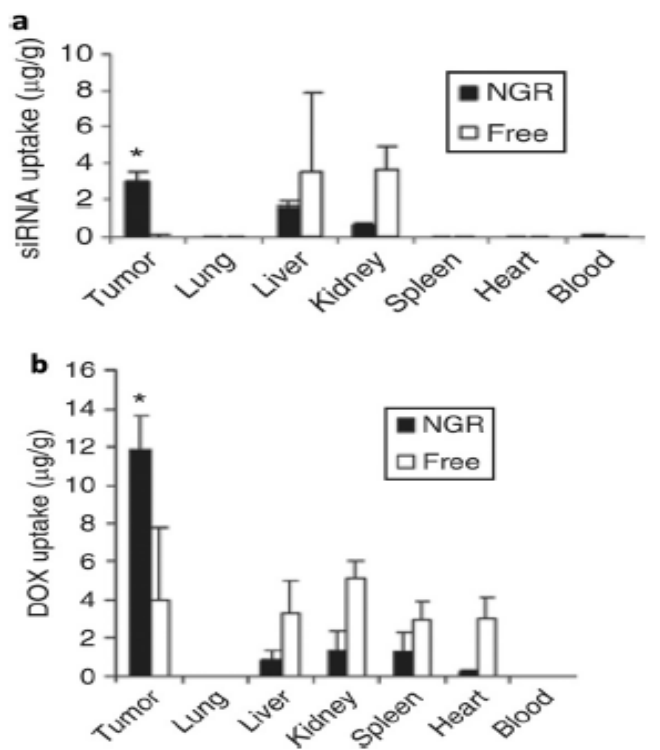

Figure 5: Tissue distribution of FITC-siRNA (a) and DOX (b) delivered with LPD-PEG-NGR (NGR). Data = mean $\pm S D, n=3$. * $p<0.05$ compared with free siRNA or DOX (Free) [118]. 


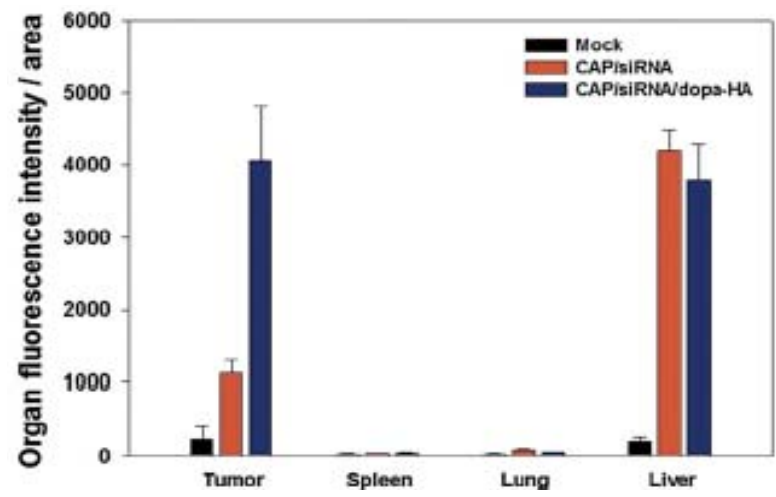

Figure 6: Normalized organ distribution of Cy5. 5-siRNA delivered by CAP/ siRNA and CAP/siRNA/dopa-HA. Normalized organ fluorescence intensity was obtained by dividing the fluorescence intensity of the organ by the area of the organ using image analysis software [119].

h post-injection, the fluorescent signals of siRNA and doxorubicin delivered as LPD-PEGNGR NPs were mainly detected in tumor, followed by the liver and kidney, whereas free siRNA was mainly seen in the liver and kidney and free doxorubicin was broadly seen in the tumor, liver, kidney, spleen, and heart, respectively (Figure 5) [118].

A CD44-targeted, inorganic siRNA delivery system was prepared by combining Calcium Phosphate (CaP)-siRNA complex and 3,4-Dihydroxy-L-Phenylalanine (dopa)-conjugated HA [119]. This system took advantage of the ability of $\mathrm{CaP}$ to co-precipitate with siRNA and form condensed NPs, dopa to bind to the CaP crystals, and HA to prevent the growth of crystal size and to target CD44 and CD168 (also known as Receptor for Hyaluronan Mediated Motility, RHAMM) overexpressed in various cancer cells [119]. The CaP/ Cy5.5-labeled siRNA/dopa-HA NPs were administered IV in nude mice bearing HT29-luc tumors. Ex vivo imaging after $4 \mathrm{~h}$ showed relatively high accumulation of the NPs in the tumor and the liver but no significant signals in the spleen and the lung (Figure 6). The accumulation of $\mathrm{CaP} / \mathrm{siRNA} /$ dopa-HA in the liver was attributed to the presence of the HA receptor in hepatocytes. Without dopa-HA, $\mathrm{CaP} / \mathrm{siRNA}$ formed particles as large as $\mathrm{N} 4 \mu \mathrm{m}$, which were captured predominantly by the liver, most likely due to the size [119].

$\mathrm{CaP}$ was also used to stabilize polymeric micelles [120]. siRNA was first encapsulated in micelles of PEG-conjugated polyaspartamide derivative (poly[ $\mathrm{N}^{\prime}$-[N-(20aminoethyl)-2-aminoethyl]aspartamide]) and stabilized with $\mathrm{CaP}$ complexation [120]. BD of siRNA was examined by tracing the fluorescence of Alexa Fluor 647-labeled siRNA in transgenic mice with spontaneous pancreatic tumors. At 6 $\mathrm{h}$ after injection of the hybrid micelles, $0.9 \%$ and $1.5 \%$ of the injected siRNA were found in each gram of pancreas/tumor and kidney, respectively, which corresponded to 6 times (pancreas/tumor) and half (kidney) the levels of naked siRNA, with no significant difference in other organs [120]. The siRNA/micelles accumulated in tumors achieved $61 \%$ reporter gene silencing at $24 \mathrm{~h}$ after injection, whereas scrambled siRNA/micelles had no effect [120].

A hybrid of cationic lipid and polymer NPs was used for the delivery of CDK1 siRNA for the therapy of Triple Negative Breast Cancer (TNBC) [38]. siRNA was encapsulated in PLA-PEG block-copolymer by the double emulsion method. Here, cationic cholesterol derivative was included in the organic phase to help condense siRNA in the NPs. Upon IV administration to SUM149 tumor bearing mice, Cy5-siRNA encapsulated in NPs showed persistent signals in the tumor, liver, spleen and kidney up to $72 \mathrm{~h}$ post-injection, whereas free Cy5-siRNA was barely seen at $12 \mathrm{~h}$ after injection [38]. At a dose of $2 \mathrm{mg} / \mathrm{kg}$ every other day, CDK siRNA/NP system suppressed the growth of SUM149 and BT549 xenograft tumors, an effect comparable to $50 \mathrm{mg} / \mathrm{kg}$ dinaciclib (a known CDK1 inhibitor), whereas neither free CDK1 siRNA nor scrambled siRNA in NPs was effective. Real-time PCR and Western blot of tumor tissues found that CDK1 siRNA-loaded NPs suppressed the levels of CDK1 mRNA and $\mathrm{CDK} 1$ protein expression levels, respectively, confirming that the tumor suppression was mediated by CDK1 silencing in tumors [38].

To enhance the formation and stability of siRNA-carrier complex, Kim et al. used a polymerized siRNA (poly-siRNA), where several siRNA molecules were linked to one another via disulfide bond, and Thiolated Human Serum Albumin (tHSA), which formed a stable complex with the poly-siRNA via intermolecular disulfide crosslinking [121]. The poly-siRNA/tHSA complex was systemically delivered to mice bearing Squamous Cell Carcinoma (SCC7) and human Prostatic Carcinoma (PC-3) tumors. siRNA was labeled with Cy5.5 fluorescence dye, and the fluorescence intensity of each organ was measured by ex vivo imaging [121]. Overall, poly-siRNA/ tHSA complex showed a stronger fluorescence signal throughout the whole body than free poly-siRNA, indicating relatively good stability of poly-siRNA/tHSA NPs [121]. Ex vivo imaging of organs at $24 \mathrm{~h}$ after intravenous injection revealed that animals treated with naked poly-siRNA had relatively high fluorescence intensity in the liver, kidney, and tumor, whereas those treated with poly-siRNAtHSA complex did predominantly in tumors [121]. Consistently, poly-VEGF siRNA/tHSA showed superior anti-cancer effects to that of a complex containing poly-scrambled siRNA through inhibition of tumor angiogenesis [121]. This group later replaced tHSA with Thiolated Glycol Chitosan (tGC) for the delivery of poly-siRNA and observed a similar pattern-relatively high fluorescence level in tumor as compared to that of naked poly-siRNA [40].

Tracking radiolabeled siRNA: BD of the CDP-based siRNA NPs (discussed in Section. 3.2) was evaluated using siRNA labeled with $64 \mathrm{Cu}$ and Positron Emission Tomography (PET)-Computer Tomography (CT) in vivo imaging [114]. Free 64Cu-DOTAconjugated siRNA showed rapid blood clearance through liver accumulation $(23 \% \mathrm{ID} / \mathrm{cm} 3$ at $60 \mathrm{~min})$ and kidney filtration followed by the bladder accumulation $(73 \% \mathrm{ID} / \mathrm{cm} 3$ at $60 \mathrm{~min}) .64 \mathrm{Cu}-$ DOTAsiRNA packaged in Transferrin Receptor (TfR)-targeted CDP NPs showed similar BD to that of naked 64Cu-DOTA-siRNA, except for slightly higher liver accumulation $(26 \% \mathrm{ID} / \mathrm{cm} 3$ at $60 \mathrm{~min})$ and a delayed peak in kidney accumulation [114]. In both cases, \% injected dose per $\mathrm{cm} 3$ tumor was no higher than $2 \%$.

Swart et al. used ${ }^{3} \mathrm{H}$-labeled siRNA to study BD of siRNA delivered with LNPs [110]. BD of siRNA/LNPs was estimated by Quantitative Whole-Body Autoradiography (QWBA) and Matrix-Assisted Laser Desorption Ionization Mass Spectrometry Imaging (MALDI-MSI) techniques, where QWBA measured the radiolabeled siRNA and MALDI-MSI measured the cationic lipid component. Following a single intravenous administration, animals treated with free siRNA 


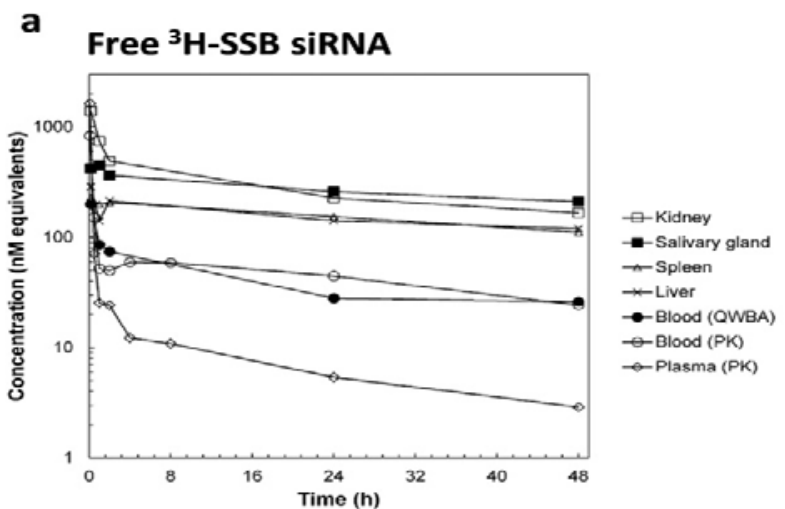

C ${ }^{3} \mathrm{H}-\mathrm{SSB}$ SIRNA (
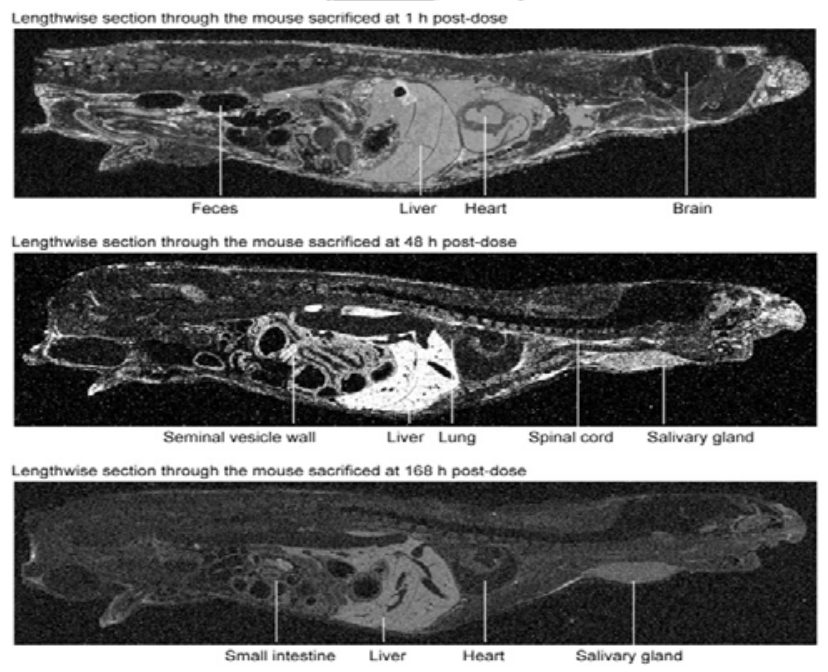

Figure 7: (a) Concentration-time profiles of radiolabeled naked 3H-SSB siRNA in dried blood, plasma, and selected tissues [108]; (b) concentration-time profiles of radiolabeled 3H-SSB siRNA in LNP in dried blood, plasma, and selected tissues; (c) selected whole-body autoradioluminographs and (d) selected whole-body MALDI-MS images at 1,48 , and $168 \mathrm{~h}$ [110] after a single intravenous administration of free $3 \mathrm{H}-\mathrm{SSB}$ siRNA(5 mg/kg siRNA) or [3H]-SBB siRNAin LNP vehicle (2.5 $\mathrm{mg} / \mathrm{kg}$ siRNA) tomale CD-1 mice. In (c), the whitest area corresponds to the highest concentration of radiolabeled siRNA. In (d), the whitest area corresponds to the highest concentration of DLin-KC2-DMA (one of the main components of the LNP vehicle).

Reprinted from References [108,110]. Copyright $(2013,2014)$ The American Society for Pharmacology and Experimental Therapeutics.

showed the highest radioactivity in kidney and salivary gland, and the radioactivity in different organs declined in a similar pattern (Figure 7a) [108]. In contrast, animals treated with siRNA/LNPs showed the highest radioactivity of siRNA in the spleen and liver, which lasted over $168 \mathrm{~h}$, whereas the blood level radioactivity gradually decreased (Figure 7b) [110]. MALDI-MSI found similar distribution of the cationic lipid as that of siRNA radioactivity, suggesting that siRNA and lipid circulated together and co-distributed as a LNP complex (Figure $7 \mathrm{c}$ and $\mathrm{d}$ ).

Harashima et al. evaluated the BD of siRNA delivered with MEND by tracking siRNA and the carrier separately [37]. Here, siRNA was labeled with 32P and the carrier with $3 \mathrm{H}$. Both siRNA and the carrier showed significant increase in tumor accumulation with PEGylation of the MEND. According to the radioactivity measurement, the levels of tumor accumulation of siRNA delivered with MEND and PEG-MEND were $3.0 \% \mathrm{ID} / \mathrm{g}$ of tumor and $5.1 \% \mathrm{ID} / \mathrm{g}$ of tumor, respectively. On the other hand, when measured by the stem-loop primer-mediated qRTPCR, which measured full-length siRNA, the

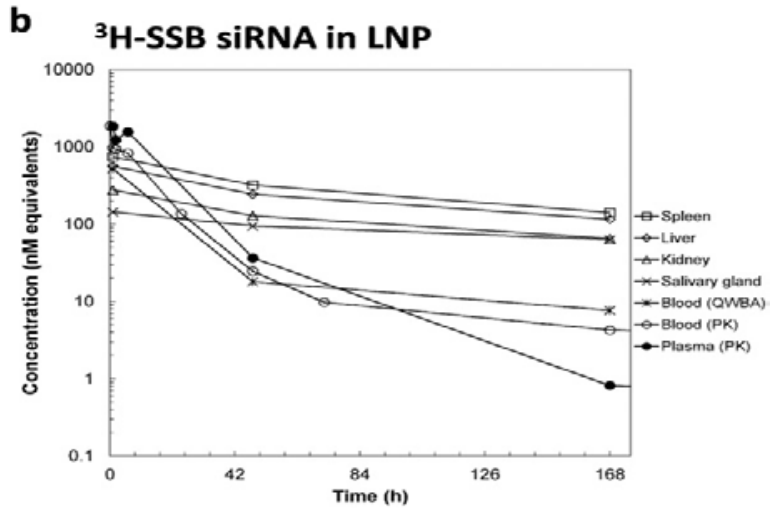

d DLin-KC2-DMA (siRNA/LNP)
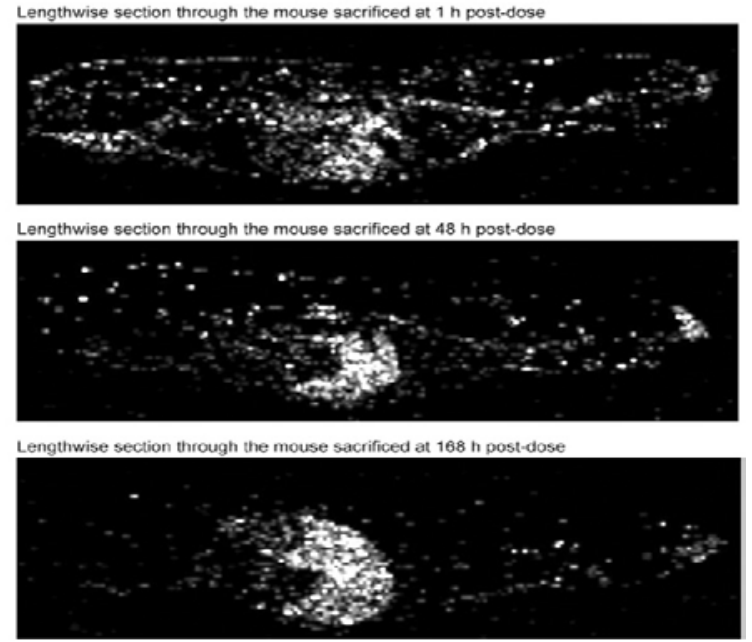

values were much lower: $0.0079 \% \mathrm{ID} / \mathrm{g}$ tumor (siRNA by MEND) and $1.9 \% \mathrm{ID} / \mathrm{g}$ tumor (siRNA by PEG-MEND). ${ }^{32} \mathrm{P}$-labeled siRNA showed differential organ distribution according to the delivery methods (free, MEND, PEG-MEND) (Figure 8a). It is worthy to note that the radioactivity of free siRNA was detected in the liver, spleen, kidney, and lung $6 \mathrm{~h}$ after injection, but the stem loop qRT-PCR did not detect siRNA in any of these organs (Figure 8b). This discrepancy strongly suggests that the radioactivity measurement may have overestimated the amount of siRNA by counting catabolites of the labeled siRNA as well. BD of siRNA indeed coincided better with that of carriers when measured with the stem-loop qRT-PCR [37].

Tracking siRNA itself: With the notion that the labeled siRNA may be degraded to inactive catabolites, alternative methods are used to detect siRNA itself instead of labels. For example, Northern blotting was used to determine the integrity of siRNA and complement quantitative measurement based on radioactivity counting [109]. Various formulations including chitosan, liposome, or JetPEI NPs were injected intravenously into mice as complexes 

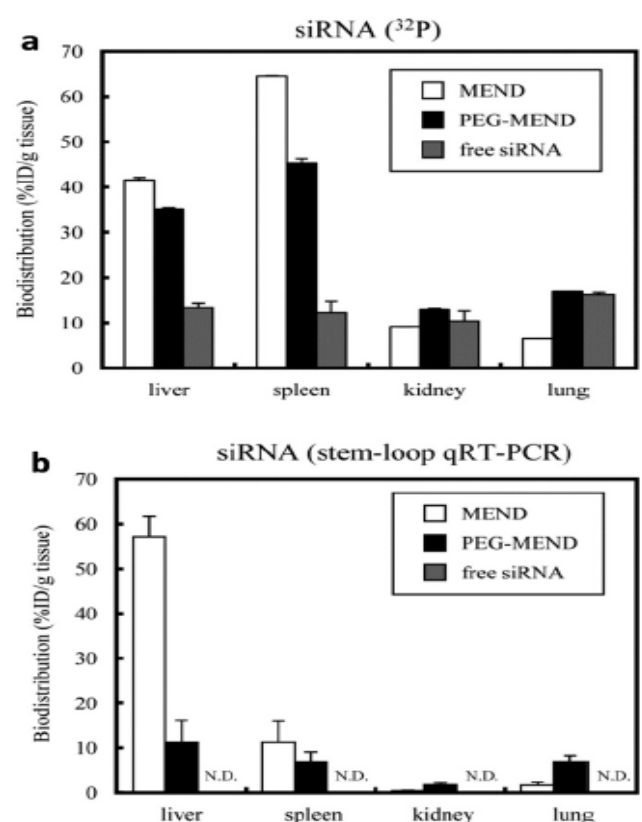

Figure 8: Comparison of the methodology between radioisotope and stemloop qRT-PCR methods. Accumulations in liver, spleen, kidney and lung 6 $\mathrm{h}$ after injection were measured by the two methodologies. Free siRNA and formulated siRNA in these organs were determined by using radioisotope (a) and stem-loop qRT-PCR method (b). N.D.: not detected.

Reprinted from Reference [37]. Copyright (2013) Nature Publishing Group.

with ${ }^{32} \mathrm{P}$-labeled siRNA. The radioactivity measurement found that liposomal formulation increased the accumulation of siRNA in the lung five- to tenfold higher than other organs (Figure 9a), with 5\% of 30-minute levels still present at $24 \mathrm{~h}$ (Figure 9b). Similarly, JetPEI/ siRNA complex showed greater levels in the lung (two- to tenfold) than in the other organs (Figure 9a). On the other hand, chitosan/ siRNA complex showed different organ distribution patternswith pronounced accumulation in the kidney (Figure 9a). The Northern blotting analysis with total RNA extracted from tissues showed consistent patterns over $24 \mathrm{~h}$, confirming the validity of radioactive label as a marker of intact siRNA [109].

Alternatively, qPCR was employed to study BD of siRNA delivered with LNP [122]. Seven organs of interest were collected at different time points, and the level of siRNA was measured with the stem-loop qPCR. At 0.5 and $2 \mathrm{~h}$ post-IV injection, the siRNA levels were highest in the liver, followed by the spleen and kidney, with little in the lung and heart, and almost none in the duodenum and brain. Reflecting the siRNA distribution, the greatest level of target mRNA knockdown was observed in the liver (85\%) and spleen (25\%), with no detectable knockdown in the lung, kidney, heart, duodenum, or brain [122].

Tracking carriers: Carrier concentrations in tissues are sometimes measured as an indirect measure of siRNA distribution. Chen et al. developed a new carrier of siRNA based on HA, hydrophobic ally modified for self-assembly formation, conjugated with a phosphate receptor Zn (II)-Dipicolylamine (DPA/Zn) for RNA binding, and stabilized with $\mathrm{CaP}$ surface layer [123]. BD of the siRNA/Carrier Assembly (CaP-HDz/siLuc-NFs) was studied by tracking Cy5.5labeled carriers in a Human Colon Cancer (HCT116) xenograft

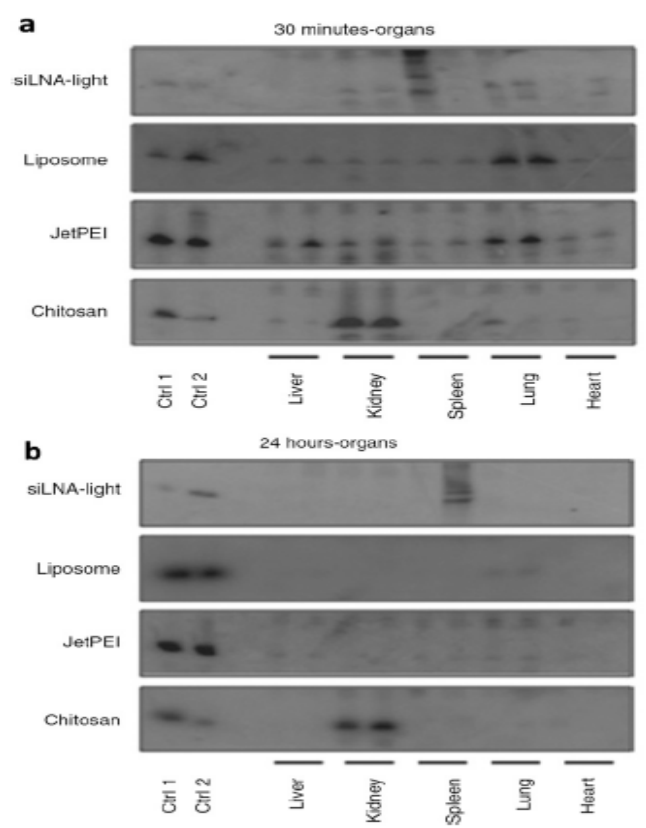

Figure 9: Organ distribution of siRNA delivered with different carriers at 30 min (a) or $24 \mathrm{~h}$ (b) after IV injection, analyzed with Northern blotting. Lane 1: 1.5-ng duplexes (Ctrl 1); lane 2: 1 ng siRNA/NP complex (Ctrl 2); lane 3 blank; lanes 4-13: duplexes or siRNA/NP complex in organs. Ctrl, control; LNA, locked nucleic acid; siLNA, LNA-modified siRNA; siLNA-light, lightly LNA-modified siRNA.

Reprinted with permission from Reference [109]. Copyright (2009) Nature Publishing Group.

mouse model. From $3 \mathrm{~h}$ post-administration, tumors showed strong fluorescence, which reached themaximumat $6 \mathrm{~h}$ and lasted until 48 $\mathrm{h}$ post-injection (Figure 10a). Ex vivo images exhibited consistently strong fluorescence intensities in tumors. Noticeable fluorescence signal was also found in the liver, lung, and kidney at $48 \mathrm{~h}$ after injection (Figure 10b). As an indirect measure of the siRNA integrity, a model siRNA silencing the luciferase-expressing gene (siLuc) was delivered with the $\mathrm{CaP}-\mathrm{HDz}$ carrier, showing $79.4 \%$ reduction of luminescence signal in tumor (Figure 10c and d).

Mirkin et al. developed Spherical Nucleic Acid (SNA) gold $\mathrm{NP}$ conjugates as a carrier of siRNA, where siRNA duplexes were conjugated to an inorganic gold NP core via thiol-gold bond, forming densely packed, highly oriented nucleic acid corona around the core [124]. BD of SNA particles was evaluated in Glioblastoma Multiform (GBM)-bearing mice based on the level of Au in the tissue by ICPMS. Similar to other siRNA delivery systems, most Au was detected in the liver and spleen after $24 \mathrm{~h}$, and $1 \%$ of the total SNA injected was found in the brain tumor. The delivery of intact siRNA was confirmed by evaluating the silencing effect of siRNA targeting Bcl2Like12 (Bcl2L12) oncogene and survival of GBM-bearing mice [124].

BD of M-MSN (discussed in Section. 3.1), containing iron in the core, was studied by measuring the iron level in organs by Atomic Absorption Analysis (AAS) [31]. M-MSN NPs loaded with siRNA were injected to A549 lung cancer bearing mice. One day after injection, $10 \%$ of the total administered NPs accumulated in the tumor, and $\sim 4 \%$ remained after 3 days. The highest iron concentration was found in the liver ( $27 \% \mathrm{ID} / \mathrm{g})$, followed by the lung $(\sim 15 \% \mathrm{ID} / \mathrm{g})$, spleen 
a

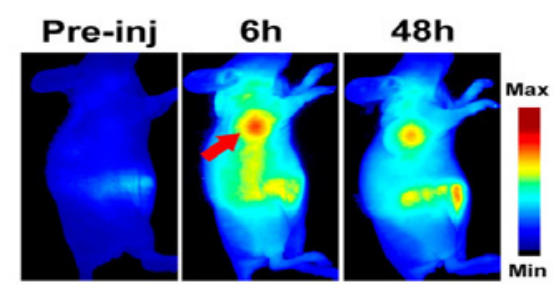

C

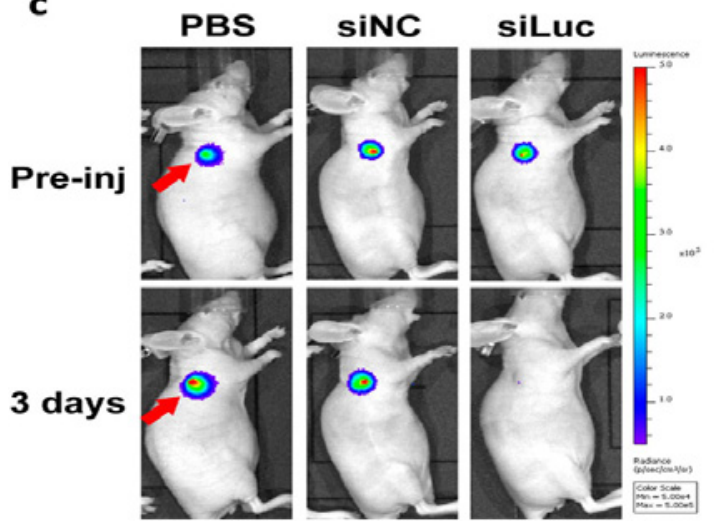

b

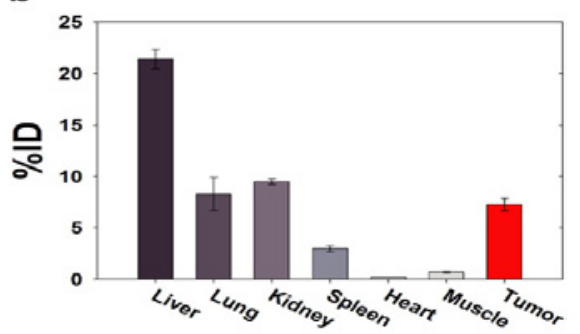

d

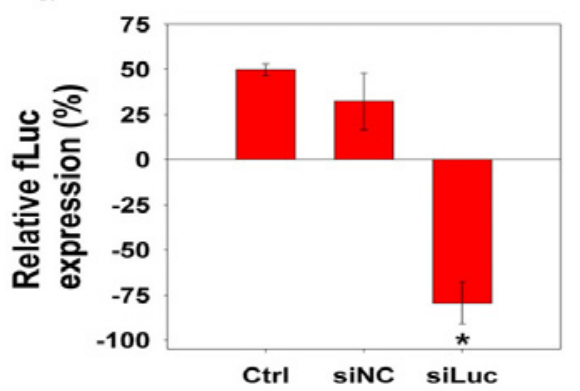

Figure 10: In vivo monitoring of tumor-targeting and gene silencing effect of CaP-HDz/siRNA-NFs. (a) In vivo near-infrared fluorescence (NIRF) imaging of HCT116 tumor-bearing mice systemically administered with CaP-HDz/siLuc-NFs labeled with Cy5.5. (b) Quantitative analysis of fluorescence intensities at the major organs and tumor tissues of mice treated with CaP-HDz/siLuc-NFs labeled with Cy5.5 $48 \mathrm{~h}$ after IV injection. (c) In vivo Bioluminescence Imaging (BLI) of fLuc gene expression in fLuc-expressing HCT116 tumor-bearing mice intravenously injected with PBS, free siLuc, or CaP-HDz/siLuc-NFs (280 $\mu \mathrm{L}$; RNA = 700 pmol). (d) Quantitative analysis of fLuc expression at tumors after intravenous injection of CaPHDz/ siLuc-NFs into the fLuc-expressing HCT116 tumor mice ( $\mathrm{n}=4$ ). Red arrow indicates tumor site; * $p<0.005$ vs control or siNC

Reprinted with permission from Reference [123]

( 14\% ID/g) and kidney ( 4\% ID/g) after $24 \mathrm{~h}$ (Figure 11a). Separate tracking of the fluorescently labeled siRNA loaded in M-MSN revealed that the carrier distribution was consistent with siRNA distribution, which was significantly higher than that of free siRNA. Fluorescence images of excised mouse organs (brain, tumor, spleen, lung, kidney, heart, stomach and liver) obtained $24 \mathrm{~h}$ after injection of the NPs showed relatively high siRNA accumulation in the liver, lung, spleen and kidney as well as in tumor. In contrast, organs from the animals receiving free siRNA showed little fluorescence except for the liver and kidney (Figure 11b) [31].

Tracking carriers may serve as a surrogate of siRNA in a BD study if siRNA and carriers remain stable in circulation, but this may not be always a valid assumption. Escriou et al. tracked carriers and siRNA, separately labeled with distinct fluorescent dyes, and found different BD patterns [125]. They used liposomes containing cationic lipid (DOPE) and an anionic polymer (Polyglutamate, PG) as a complexation aid and studied the effect of PG on $\mathrm{BD}$ of the complexes in the lung and liver. The tissue level of lipid remained constant irrespective of the presence of PG (Figure 12a). However, siRNA level increased by $2-3$ folds with PG (Figure $12 \mathrm{~b}$ ), which was interpreted as a consequence of the enhanced stability of the PG-containing complexes [125]. The conclusion would have been different if they measured the level of carriers only.

Targeted vs. non-targeted: One notable trend observed with the so-called 'targeted' gene carriers is that the targeting ligands seemed to play a minimal role in changing initial BD of siRNA. The dual- stabilized polymeric micelles, discussed in Section 3.1, were further decorated with Cyclic RGD (cRGD) peptide ligands for tumortargeting [105]. Ex vivo organ imaging at $4 \mathrm{~h}$ after IV injection found that BD of Cy5-labeled siRNA fluorescence was similar between nontargeted and targeted micelles, with the majority of signals found in the kidney and liver. A difference attributable to cRGD was seen as slight increase in tumor accumulation (Figure 13) [105].

A comparable observation was made in an earlier study with TfRtargeted CDP-basedNPs (discussed in Section. 3.2), where both nontargeted and targeted NPs showed similar BD and tumor localization of siRNA (Figure 14) [114]. Despite the similarity in BD, siRNA delivered with TfR-targeted NPs showed $50 \%$ greater gene silencing effect than non-targeted NPs, indicating more efficient entry of the targeted NPs into tumor cells [114]. This study suggests that the contribution of a targeting molecule is to facilitate cellular uptake of the NPs rather than to actively guide the NPs to the target tissues as the name implies [114]. On the other hand, other studies show the increase in overall tumor localization of targeted NPs [126,127]. In interpreting those studies, it will be worthwhile to consider that the increased tumor accumulation is likely a net result of the EPRdriven extravasation of NPs (initial BD: targeted $\approx$ non-targeted) and efficient cellular uptake and retention at target cells (targeted $>$ nontargeted).

\section{Pharmacological effects of siRNA therapeutics}

Due to the favorable BD of siRNA delivery systems, the liver and lung are among the primary targets of siRNA therapeutics. 


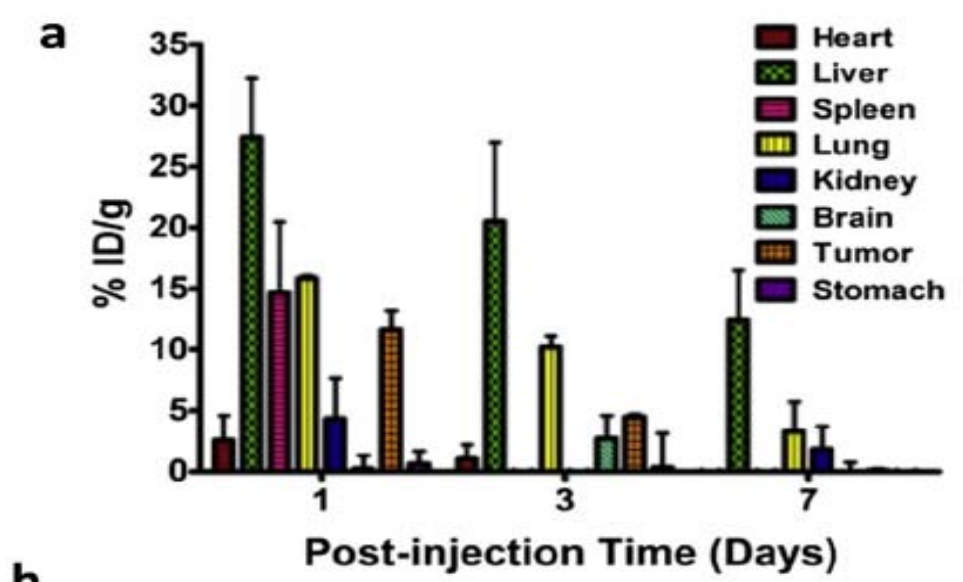

M-MSN_CY3-SIRNA@PEI-PEG-KALA

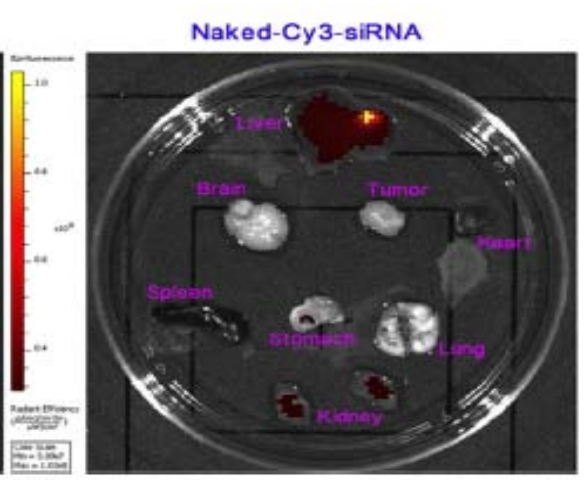

Figure 11: (a) Distribution profile of M-MSN_NC siRNA@PEI-PEG-KALA in tumor and various organs of tumor-bearing mice after tail vein administration. The $\%$ of NP distribution was determined from measurement of Fe element content at different time points ( 1 day, 3 days, 7 days after particle injection), subtracting the basal Fe content of tumor bearing mice without particle injection $(n=3)$. (b) Fluorescence images of excised mouse organs (heart, liver, spleen, lung, kidney, brain, tumor and stomach) 24 h after injection of M-MSN_Cy3-siRNA@ PEI-PEG-KALA (left), naked-Cy3-siRNA (right) using an IVIS spectrum imaging system with excitation and emission wavelengths of 554/568 $\mathrm{nm}$.

Reprinted with permission from Reference [31]. Copyright (2014) Elsevier.

This section provides a brief overview of recent preclinical studies on pharmacological effects of siRNA therapeutics in liver and lung diseases.

\section{Liver diseases}

HCC: Initial efforts to treat HCC with siRNA involved free siRNA injection. siRNA targeting VEGF expression in hepatoma and endothelial cells with no specific carrier system was tested in a murine orthotopic hepatoma model [61]. Animals were injected with $200 \mu \mathrm{g} / \mathrm{kg}$ of siRNAVEGF intraperitoneally, every 2 days for 14 days starting from $24 \mathrm{~h}$ prior to tumor cell inoculation. When determined terminally, tumor burden was reduced by $63 \%$ [61]. The antitumor efficacy was attributed to the inhibition of tumor angiogenesis, corresponding to intratumoral microvessel density [61]. Similarly, siRNA targeting antiapoptotic protein heme oxygenase 1 (HO-1) was intraperitoneally injected to immune-competent mice bearing HO-1+ Hepa129 tumors in the liver and reduced tumor growth by $50 \%$ with no damages in normal organs [128]. The authors [129] attributed this effect to proapoptotic and possibly antiangiogenic activity of siHO-1 [128].

For improving siRNA delivery to the liver andHCC, NPs based on cationic lipid such as 1,2-dioleyloxy-3-trimethylammonium propane (DOTAP) are widely used as a carrier of siRNA. Schmitz et al. made a complex of VEGF-targeting siRNA with DOTAP and injected the complex intraperitoneally multiple times to mice with pre-existing liver fibrosis as well as orthotopic HCC (Hepa129 cells injected to the left liver lobe) [130]. The VEGF-siRNA/DOTAP complexes resulted in significant reduction in the number of HCC satellites in the liver ( $82 \%$ mice had $<30$ satellites), whereas free VEGF-siRNA and control siRNA had a minimal effect $(22.1 \%$ and $12.5 \%$ mice with $<30$ satellites, respectively). DOTAP helped VEGFsiRNA enter HCC satellites and silence VEGF expression in hepatic tissues. However, the effect of the internalized VEGFsiRNA-DOTAP complex on tumors was more likely through immune activation via interferon-1 upregulation than VEGF silencing [130]. In fact, intratumoral VEGF expression was not reduced by VEGF-siRNA/ DOTAP complexes but rather increased [130]. More recently, Shen et al. screened several lipid NPs for optimal siRNA delivery to HCC and identified a combination of lipids that showed significant anti-tumor effect with cancer-targeting siRNAs [131]. An interesting note in this study is that good in vitro transfection efficiency did not necessarily translate to good in vivo silencing effect in orthotopic HCC tumors, which indicates the significance of circulation stability of gene-carrier complexes [131]. 

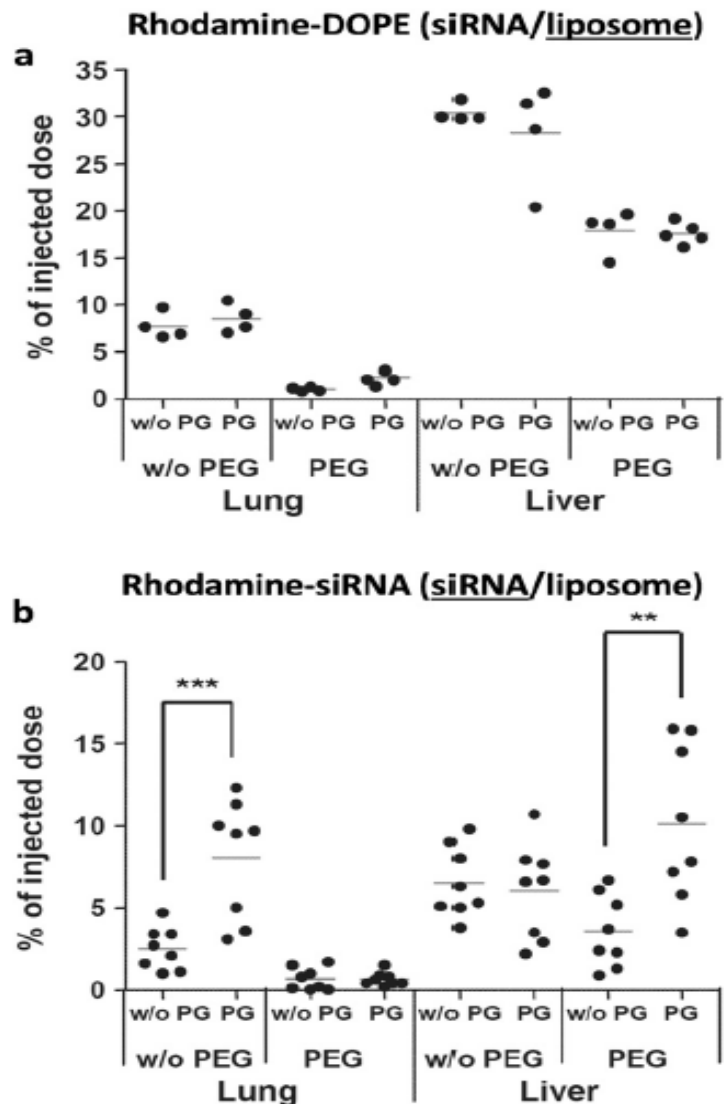

Figure 12: Lipoplexes recovery after IV injection. siRNA lipoplexes, formed with or without $P G$ at a charge ratio of 8 , were labeledwith fluorescent lipid (a, $5 \%$ Rhoda mine-DOPE incorporated in cationic liposome) or with fluorescent siRNA (b, 5' Rhoda mine-labeled siRNA used to form siRNA lipoplexes) and IV injected (10 $\mu \mathrm{g}$ siRNA/mouse). Two hours post injection, lung and liver were removed and fluorescent lipid (a) or fluorescent siRNA (b) were extracted and quantified; $n=4$ (a) or $n=8$ (b), ${ }^{* *} p<0.005$; ${ }^{* * *} p<0.002$ Reprinted with permission from Reference [125]. Copyright (2011) Elsevier.

To further improve cell specificity of siRNA delivery, cellinteractive ligands have been added to the carrier. For example, a model siRNA was encapsulated in PEGylated DOTAP-based immunoliposomes decorated with anti-EGFR Fab' [132]. A BD study in an orthotopic mouse model of HCC showed that the immunoliposomes accumulated in the liver and were taken up by HCC cells to greater extents than non-targeted liposomes, achieving higher silencing effect on the model luciferase gene expression [132]. This system was later used for the co-delivery of doxorubicin and siRNA targeting RRM2, a gene important for DNA synthesis and repair and highly expressed in HCC [126]. The siRNA and drug delivered with immunoliposomes showed $50-60 \%$ ID/g in the HCC tumors, compared to $20-30 \% \mathrm{ID} / \mathrm{g}$ of non-targeted liposomes, $8 \mathrm{~h}$ after injection. Accordingly, animals treated with siRNA-RRM2 and doxorubicin in immunoliposomes showed the most significant retardation of tumor growth, compared to those receiving each treatment or dual loads in non-targeted liposomes [126].

Liver infections: Due to the preferable BD in the liver, hepatitis infections like HBV and HCV were one of the earliest targets of siRNA therapeutics. For example, siRNA targeting the $\mathrm{S}$ region of HBV RNA was delivered with SNALPs based on a mixture of cationic

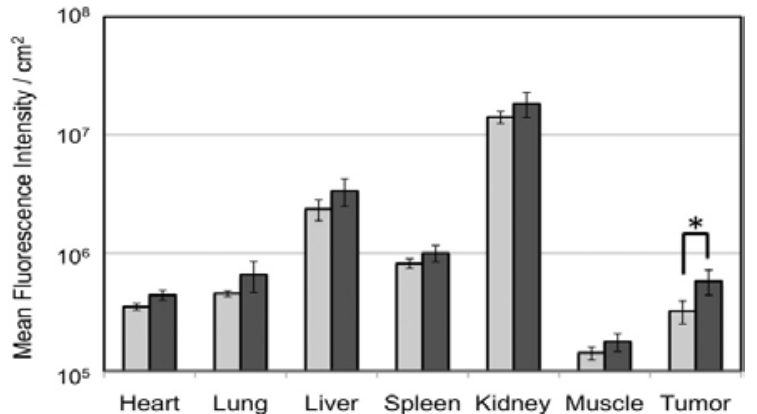

Figure 13: BD of non-targeted (gray bars) or actively-targeted (black bars) Chol/Cy5-siRNA micelles (1.8 nmol siRNA/mouse) at $4 \mathrm{~h}$ after IV injection via tail vein of $B A L B / c$ nude mice.

Reprinted with permission from Reference [105]. Copyright (2014) Elsevier.

a
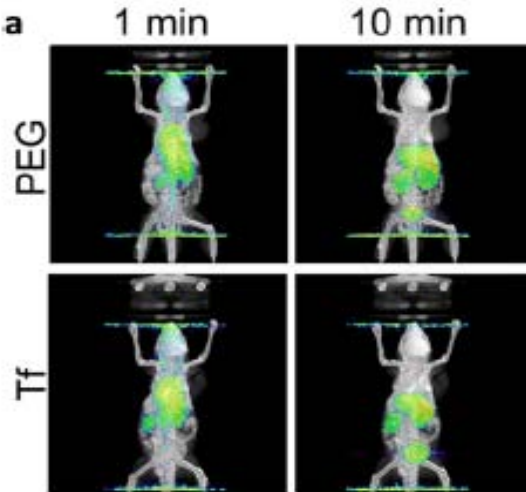

$60 \mathrm{~min}$

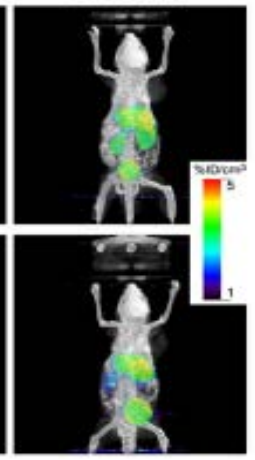

b

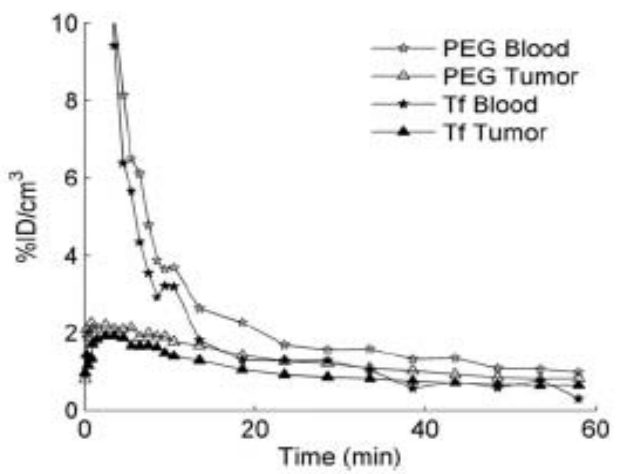

Figure 14: Tissue distribution of 64Cu-DOTA-siRNA delivered by targeted (Tf) and nontargeted (PEG) NPs. (a) Fused micro-PET/CT images of mice at 1, 10 and 60 min after injection. (b) Blood clearance and tumor localization of Tf-targeted and non-targeted siRNA NPs.

Reprinted with permission from Reference [114]. Copyright (2007) National Academy of Sciences, USA.

and fusogenic lipids $[133,134]$. Here, $2^{\prime}-\mathrm{OH}$ of siRNA was chemically modified to increase the resistance against nucleases [133]. IVinjected SNALP particles were accumulated predominantly in the liver $(28 \%)$ with minimal accumulation in other organs $(8.2 \%$ in spleen and $0.3 \%$ in the lung) by $24 \mathrm{~h}$ after injection [133]. Reflecting the high liver accumulation, siRNA delivered with SNALPs achieved a significant reduction of the level of HBV DNA copies and HBsAg proteins for 7 days after dosing [133]. In another case, siRNAs targeting HBV transcript sites 1407 or 1794 were delivered with lipid 


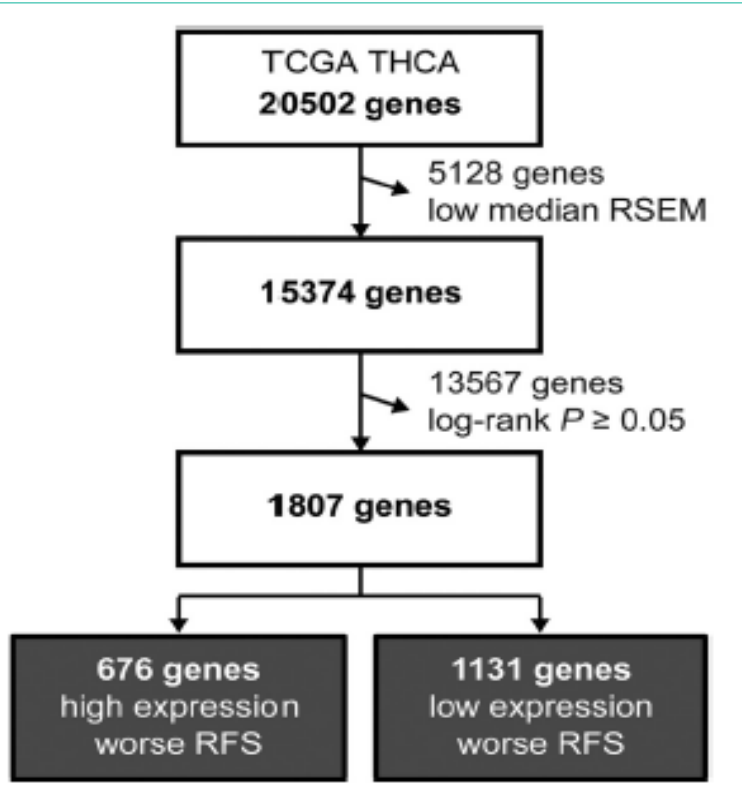

Figure 15: Study flowchart. RFS, Recurrence-free survival; RSEM, RNASeq by expectation maximization; TCGA, The Cancer Genome Atlas; THCA, thyroid cancer.

assemblies based on three different lipids, including one conjugated to PEG2000 by oxime linkages, which could be cleaved at $\mathrm{pH}$ lower than 5.5 [78]. A BD study with the radiolabeled assemblies found that regardless of the PEG concentration in the formulation, most of the dose $(>50 \%)$ was detected in the liver after $1 \mathrm{~h}$ post-injection, and other organs such as spleen, kidney, blood and lung showedminimal accumulation of the particles. Accordingly, HBV transgenic mice receiving the siRNA-lipid assemblies showed significant reduction in HBV replication, indicated by the reduced levels of HBV mRNA and $\mathrm{HBeAg}$ proteins in the liver and HBsAg in serum, equivalent to daily intraperitoneal treatment of Lamivudine, a licensed drug for HBV treatment [78]. Later, this group introduced a new cationic lipid DODAG ( $\mathrm{N}^{\prime}, \mathrm{N}^{\prime}$-dioctadecyl-N-4,8-diaza-10-aminodecanoylglycylamide) and achieved a similarly effective knock-down of HBV infection [135].

siRNA targeting 5'-UTR of HCV genome was encapsulated in liposomes composed of a cationic lipid, Phosphatidylcholine (PC) and lactosylated phosphatidylethanol, which targeted the asialoglycoprotein receptor on hepatocytes [86]. A BD study with a fluorescently labeled (Alexa-568) siRNA in BALB/c mice showed preferential accumulation of siRNA in the liver in $30 \mathrm{~min}$ after injection with the lactosylated liposomes, whereas those delivered with non-lactosylated liposomes showed equally strong signals in the spleen and liver [86]. In a pharmacodynamics study with an HCV transgenic mouse model, siRNA targeting 325-344 nucleotides of HCV genome, delivered with the lactosylated liposomes, efficiently suppressed HCV protein expression in a dose dependent manner 48 $\mathrm{h}$ after a single treatment [86]. Similarly, siRNA was incorporated in cationic liposomes ('DTC-apo') composed of DOTAP and cholesterol decorated with apolipoprotein A-1, the protein component of highdensity lipoprotein (HDL) targeting hepatocytes. ABD study using fluorescently labeled 21-mer dsDNA encapsulated in DTC-apo showed relatively high fluorescence intensity in the liver compared to other organs like kidney, lung, and spleen [89]. Without the apolipoprotein ligand, fluorescence was preferentially seen in the lung and spleen [89]. In vivo silencing effect was tested in a HCV mouse model created with hydrodynamic injection of plasmid DNA expressing viral structural proteins. HCV-specific siRNA/DTC-apo complex inhibited viral gene expression by $65 \%$ in the liver at $2 \mathrm{mg} /$ $\mathrm{kg}$ siRNA on day 2 post administration. The extent and duration of siRNA were further improved by 2'-O-methylmodification of siRNA [89]. ApolipoproteinA-1was later replaced with a recombinant form of apolipoprotein (rhApo) derived from Escherichia coli to avoid the safety concern (e.g., pathogen contamination) related to the origin (plasma) [136]. In addition to siRNA, synthetic shRNA targeting the IRES of the HCV genome was incorporated in a mixture of lipids to form lipid NPs, showing long lasting potent efficacy against HCV in mice with minimal toxicity [87].

More recently, it was demonstrated that simple co-injection of a hepatocyte-targeted peptide could help deliver siRNA targeting conserved HBV sequences to the liver [77]. The peptide consisted of $\mathrm{N}$-acetylgalactosamine (NAG), a ligand with high affinity for asialoglycoprotein receptors highly expressed on the hepatocytes, and melittin-like peptide (MLP), an endosomolytic agent to facilitate endolysosomal escape of siRNA [77]. A co-injection of NAGMLP with liver-tropic cholesterol-conjugated siRNA increased the hepatic gene silencing effect in a dose-dependent manner, resulting in multilog repression of viral RNA, proteins, and viral DNA with long duration of effect in mouse models of HBV infection. This formulation is unique in that it does not require preformulation of the complex like typical siRNA delivery systems, thus reducing the complexity in large-scale manufacturing. It has recently entered phase IIa clinical trial for the treatment of chronic HBV infection (NCT02065336) [137].

As one of the primary sites for Ebola virus replication, the liver also serves as a valid target for siRNA therapy of Ebola virus infection. siRNA targeting individual regions of Zaire Ebola virus (ZEBOV) L gene was delivered with SNALPs [92]. Despite the evidence suggesting premature release of siRNA in circulation (differential BD of labeled SNALPs and siRNA), siRNA/SNALPs provided post-exposure protection to guinea pig challenged with a lethal Ebola virus. Animals challenged with ZEBOV received siRNA treatment at 1, 24, 48, 72, 96,120 , and $144 \mathrm{~h}$ after the infection. On day $30,100 \%$ survival rate $(n=5)$ was observed in the group treated with the siRNA/SNALP formulation, while the control group treated with scrambled siRNA/ SNALPs presented $20 \%$ survival rate. Consistently, the plague titer analysis on day 7 showed a significantly reduced blood level in animals treated with siRNA/SNALPs compared to the control group. Later this group encapsulated a cocktail of three siRNAs that each targeted L protein, VP24 and VP35 genes in ZEBOV in SNALPs and showed complete post-exposure protection against ZEBOV in monkeys [91]. Tekmira Pharmaceuticals commenced a Phase I clinical trial for the cocktail siRNA-SNALP formulation (TKM-100802) in Jan 2014 (NCT02041715) [138]. Two patients transported from West Africa to the United States during the 2014 outbreak of Ebola virus disease were treated with TKM-100802 and other supportive measures and recovered without serious long-term sequelae, although the actual role the siRNA formulation played in the recovery of these patients remains to be investigated [139]. 
Respiratory diseases: For systemic delivery of siRNA to the lung, cationic polymers such as PEI are frequently used as carriers [140]. In an early study by Klibanov et al., deacylated PEI was used as a carrier of siRNA to the lung [99]. Here, deacylation increased the number of protonatable nitrogens of PEI, thereby facilitating complexation with siRNA and transfection of target cells. Luc-siRNA-deacylated PEI complexes were administered to mice transfected with luciferaseencoding DNA by retroobrital injection, and the luciferase activities in different tissues were measured at $24 \mathrm{~h}$ after the treatment. The Luc-siRNA/polymer complexes showed 77 or $93 \%$ suppression of the gene expression in the lung, depending on the molecular weight of the polymer. Consistently, siRNA targeting influenza viral genes, as complexed with deacylated PEI, led to significant reduction in the virus titer in the lung of influenza-infected mice $24 \mathrm{~h}$ after injection [99]. More recently, Bolcato-Bellemin et al. used PEI as a carrier of siRNAwith sticky overhangs (ssiRNA) targeting cyclin B1 or survivin to suppress tumor progression in a lung metastasis model [141]. Here, ssiRNA formed a larger linear nucleic acid structure via hybridization of the complementary overhangs andmade a more stable complex with PEI, which survived better than a classic siRNA/PEI complex in circulation [142].

Cationic liposomes tend to accumulate in the liver and hence are popular in the delivery to the liver, but they are also used for lung delivery. McMillan et al. used cationic liposomes containing DOTAP and DOPE as a carrier of siRNA targeting lung endothelium [143]. A BD study with the liposomes labeled with a non-covalently incorporated fluorescent dye found the highest fluorescence intensity was found in the liver, followed by lung and spleen.The liposomes transfected various cell populations in the lung, including CD146+ endothelial cells and CD326+ epithelial cells. Accordingly, mice treated with lamin A/C-specific siRNA-liposomes ( $2 \mathrm{mg} / \mathrm{kg}$ siRNA) showed $80 \%$ knockdown of lamin $\mathrm{A} / \mathrm{C}$ in the lung at $48 \mathrm{~h}$ after a single IV injection, with the majority silencing occurring in the endothelial and epithelial cells [143]. A new choice of cationic lipids and combinations improved lung-specific BD of liposomes [144]. Kaufmann et al. used "DACC" liposomes containing AtuFECT01 ( $\beta$-L-arginyl-2,3-L-diaminopropionic acid-N-palmityl-Noleyl-amide trihydrochloride) as a cationic lipid for systemic administration of siRNA. When combined with cholesterol and mPEG2000-DSPE in optimal ratios, DACC liposomes delivered the most siRNA to the lung tissues at $1 \mathrm{~h}$ after systemic application, followed by the spleen and liver. On the other hand, other liposomes containingAtuFECT01 and different colipids and/or PEG-lipids showed typical BD pattern of cationic liposomes (high liver and spleen distribution) [144]. In accordance with the BD profile, DACC lipoplexes with siRNA specific for Tie-2 gene showed over $80 \%$ reduction in Tie- 2 mRNA in lung tissue of mice but no significant Tie-2 knockdown in liver, kidney and heart tissues after 3 daily injections of $2.8 \mathrm{mg}$ siRNA/ $\mathrm{kg}$ [144]. DACC lipoplexes also helped deliver siRNAs targeting other genes in the lung vasculature including CD31, responsible for multiple processes of tumorigenesis, increasing the survival rate in an experimental lung metastasis mouse model [144]. Geick et al. also found BD favorable for lung delivery of siRNA with a lipopolyamine called staramine [145]. siRNA level in each tissue wasmeasured by the stem-loop qRT PCR over 96 h post-intravenous injection. Liver accumulation was dominant immediately after the injection, but lung accumulation occurred over time, exceeding the levels in the liver, spleen, and kidney in $24 \mathrm{~h}$. Consistently, siRNA/staramine complexes showed $\sim 60 \%$ reduction of target mRNA in the lung over $96 \mathrm{~h}$ after a single administration, whereas the level of target mRNA in the liver was not significantly different from the one treated with control siRNA [145]. The siRNA retention in the lung was attributed to the affinity of nanocomplexes for the endothelial lining in the capillary bed and relatively low exposure to phagocytic cells [145].

Other types of siRNA carriers to the lung include hybrids of lipid and polymer or lipid and inorganic components. Polymeric NPs made of conjugates of low molecular weight polycation (PEI) and lipids were used for delivery of siRNA to lung endothelial cells [146]. Unlike lipid-based carriers, the lipid-polymer hybrid NPs achieved the gene silencing effect at a dose that did not affect hepatocytes or immune cells. The biological effects of siRNAs delivered with the NPs were confirmed in the lung, as an inducer of an emphysema-like phenotype (by silencing VEGFR-2 gene) or a suppressor of primary and metastatic Lewis lung carcinoma (by silencing VEGFR-1 and Dll4) [146].

In addition to systemic administration, siRNA has been directly delivered to the lung as an aerosol (intratracheal or intranasal administration in experimental studies). One of the advantages of airway delivery is the potential to achieve high local concentration of siRNA in the lung without going through blood circulation, which can compromise the stability of the siRNA/carrier complexes or siRNA itself and subject them to distribution in other MPS organs. Minko et al. administered siRNA/cationic liposome complexes via intravenous injection or intratracheal instillation to mice bearing tumors in the lung to compare the BD [147]. At 24 h postadministration, both the carrier and siRNA showed substantially high peak concentrations and long retentions in the lung compared to other organs after intratracheal administration. On the other hand, IV injection resulted in broad distribution in other organs with relatively low levels of liposomes and siRNA in the lung [147]. Kissel et al. also delivered siRNA with PEI or PEG-grafted PEI (PEG-PEI) as carriers via intratracheal instillation and observed the BD of siRNA and the polymer by single photon emission computed tomography (SPECT) and radioactivity counting of organs [148]. Both siRNA and PEG-PEI were detectable in the lung at $48 \mathrm{~h}$ after instillation. Without PEG, siRNA/PEI complexes showed differential lung accumulation of each component: negligible level of siRNA and high level of PEI (even higher than that of PEG-PEI), which suggested dissociation of the complex in the lung and preferential association of PEI with mucus and cell membranes [148]. The locally delivered EGFP-specific siRNA/PEG-PEI complexes reached bronchial cells and alveolar cells and knocked down the EGFP expression in the lung by $42 \%$ after 5 days post-instillation [148]. Airway administration is potentially a promising way of delivering siRNA to the lung; however, studies to date suggest remaining challenges in airway delivery of siRNA, including the destructive interaction with anionic components in the lung [148] and local irritation that can lead to inflammatory consequences [149].

Potential toxicity of siRNA therapeutics: siRNA with suboptimal potency can result in unintended side effects such as downregulation of off-target genes or activation of innate immune 
responses [150]. Efforts to mitigate these off-target effects include chemical modification of siRNA, redesign of the sequence, and the use of siRNA cocktails [150-152]. Toxicity may also come from the delivery systems. For example, intravenously injected lipoplexes have shown to induce the production of pro-inflammatory cytokines with signs of hepatocyte injury $[153,154]$. These pro-inflammatory effects were initially attributed to the polynucleotide part of the complex rather than the carrier $[153,154]$; however, later studies have reported intrinsic pro-inflammatory properties of some cationic lipids [155157]. PEI, the most commonly used polymeric gene carrier, shows molecular weight, structure, and dose-dependent toxicity [158]. This challenge is currently tackled by developing degradable polycations, which can be degraded into less toxic small molecules [159].

\section{DNA Recurrence-associated genes}

It is important to identify systemically recurrence-associated genes using The Cancer Genome Atlas RNA sequencing database [160]. Recurrence of papillary thyroid cancer is not uncommon, but incorporating clinicopathologic parameters to predict recurrence is suboptimal. It has been found that [160] 1,807 genes were associated with recurrence-free survival. There were 676 genes of which high expression was associated with a greater risk of recurrence. These genes were enriched in pathways involved in cell cycle regulation and DNA repair. Among 1,131 genes of which low expression was associated with recurrence, Kyoto Encyclopedia of Genes and Genomesannotated functions were metabolism, calcium signaling, glycan biosynthesis, and the Notch signaling pathway. Canonical pathways identified by Ingenuity Pathway Analysis included RXR function, nitric oxide signaling, interleukin- 8 signaling, and nutrient sensing. In addition, low expression of the majority of thyroid differentiation genes was associated with a significantly less recurrence-free survival.

The incidence of thyroid cancer, particularly papillary thyroid cancer, has been increasing rapidly in recent decades [161]. Papillary thyroid cancer tends to be biologically indolent and has an excellent prognosis. Nonetheless, more than one-quarter of patients may experience disease recurrence during long-term follow-up [162]. Several schemes, including clarification of the staging classification of the American Joint Committee on Cancer, have been developed to predict risk for death but not the risk for recurrence.

In 2009, the American Thyroid Association (ATA) first proposed a 3-level, initial risk-stratification system to predict disease recurrence and/or persistence [163]; however, the proportion of variance explained by the ATA system for risk of recurrence is suboptimal, ranging from $19 \%$ to $34 \%$ [164]. Although a new, dynamic, riskstratification system has been developed, the information required for stratification is available mainly during the follow-up period. This situation indicates a need for early identification of additional factors associated with disease recurrence.

Genetic and molecular approaches are being used increasingly for recognizing important biologic processes in oncology. The most frequent genetic alteration seen in papillary thyroid cancer is a point mutation at codon 600 of the BRAF gene (BRAFV600E) [165]. It remains debatable whether this information concerning this mutation added predictive value for disease-specific mortality or risk of recurrence beyond the current clinicopathologic information collected for tumor staging [166].
In recent years, the prognostic importance of the TERT promoter mutations in thyroid cancer has attracted much attention; nonetheless, the frequency of the TERT promoter mutations in papillary thyroid cancer is considerably less than that in poorly differentiated or anaplastic cancer [167]. Given the biologic complexity of cancer, it is unlikely to find a single target accounting for disease recurrence. A systemic approach is required to identify a gene expression signature associated with recurrent disease.

The Cancer Genome Atlas (TCGA) project is meant to produce a comprehensive atlas of cancer genomes to accelerate our understanding of the molecular basis of cancer and improve cancer prevention, detection, and therapy. The TCGA study of papillary thyroid cancer analyzed a large cohort of tumor tissue and matched normal tissues across multiple sequencing platforms [168]; however, the follow-up data were not available at the time of initial TCGA publication. In this study [160], it has been e employed a systematic approach for characterizing recurrence-associated genes and their relevant functional networks using the updated TCGA data.

Functional enrichment analyses: Recurrence-associated genes were subjected to functional enrichment analyses [160], which were conducted using 3 software packages separately: Web-based Gene Set Analysis Toolkit (WebGestalt), [169] Database for Annotation, Visualization, and Integration Discovery (DAVID), [170] and Ingenuity Pathway Analysis (Qiagen, Redwood City, CA) [171]. WebGestalt and DAVID analyses were focused mainly on the Kyoto Encyclopedia of Genes and Genomes (KEGG) annotation database $[172,173]$. In WebGestalt, the minimum number of genes for enrichment was set at 5 , and the significance analysis was performed using the hypergeometric test with the significance level set at $\mathrm{P}=.01$. In DAVID, the parameters were set to their default values.

Using the TCGA thyroid cancer database, 504 patients with data for both clinical and gene expression were analyzed. Pathologic stages I, II, III, and IV comprised 56\%, $10 \%, 22 \%$, and $11 \%$, respectively. The median follow-up duration was 29.9 months (mean, $37.7 \pm$ 32.1; range, $0.2-180.8$ months). During follow-up, 16 (3\%) patients were deceased at $39.0 \pm 24.5$ months. Recurrence was observed in 47 (9\%) patients. The median time from initial treatment to recurrence was 16.1 months (mean, $19.6 \pm 14.7$; range, $0.2-59.5$ months). As expected, an advanced pathologic stage was associated with a greater likelihood of recurrence [160].

Among 20,502 genes analyzed, the distribution of median RSEM values was significantly skewed (median, 187.0; interquartile range, 4.1-800.0). To avoid variation caused by low-level expressions, genes with a median RSEM value of less than 4.1 were excluded from analysis. A total of 15,374 (75\%) genes were applicable to the analysis of the difference in RFS between high- and lowexpression groups defined by median splits. A study flowchart is detailed in Figure 15.

There were 676 genes of which high expression was associated with a significantly lesser RFS [160]. The overlapping KEGGenriched pathways were determined at the significance levels of $\mathrm{P}$ $<.01$ in WebGestalt and $\mathrm{P}<0.1$ in DAVID, respectively. Of the 10 enriched pathways, most were biologic processes involved in cell cycle regulation and DNA repair [160]. The Kaplan-Meier estimates of RFS of several representative genes are shown in Figure 16. 

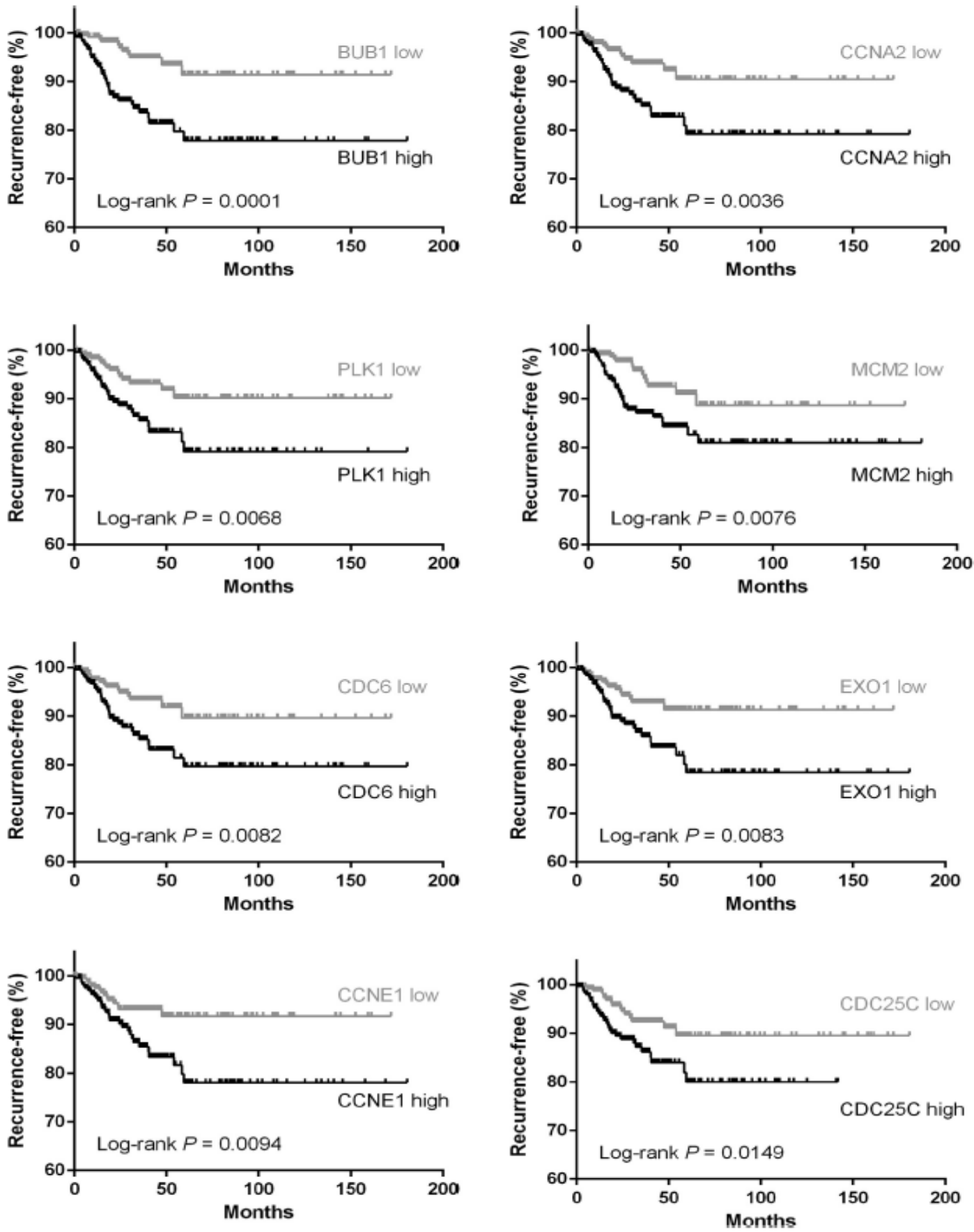

Figure 16: Kaplan-Meier recurrence-free survival of patients with papillary thyroid cancer $(n=504)$ dichotomized according to genes of which high expression was associated with recurrence.

Good concordance was observed between the enriched functional pathways identified by the KEGG module and Ingenuity Pathway Analysis (Figure 17A). The top tox lists of Ingenuity Pathway Analysis were "Cell Cycle: G2/M DNA Damage Checkpoint Regulation," "Increases Liver Hyperplasia/Hyperproliferation," "Cell Cycle: G1/S Checkpoint Regulation," "RAR Activation," and "p53 Signaling." Consistent with a recent report [174] , it has been found that expression of BRAF mRNA was not associated with RFS (logrank
$\mathrm{P}=0.76)$

In addition, we found 1,131 genes for which low expression was associated with a significantly less RFS. The complete list of these genes is reported in [160]. The 9 significantly enriched KEGG pathways identified by WebGestalt and DAVID were related to metabolism, calcium signaling, glycan biosynthesis, and the Notch signaling pathway [160]. The results appeared partially consistent with canonical pathways identified by Ingenuity Pathway Analysis 
A

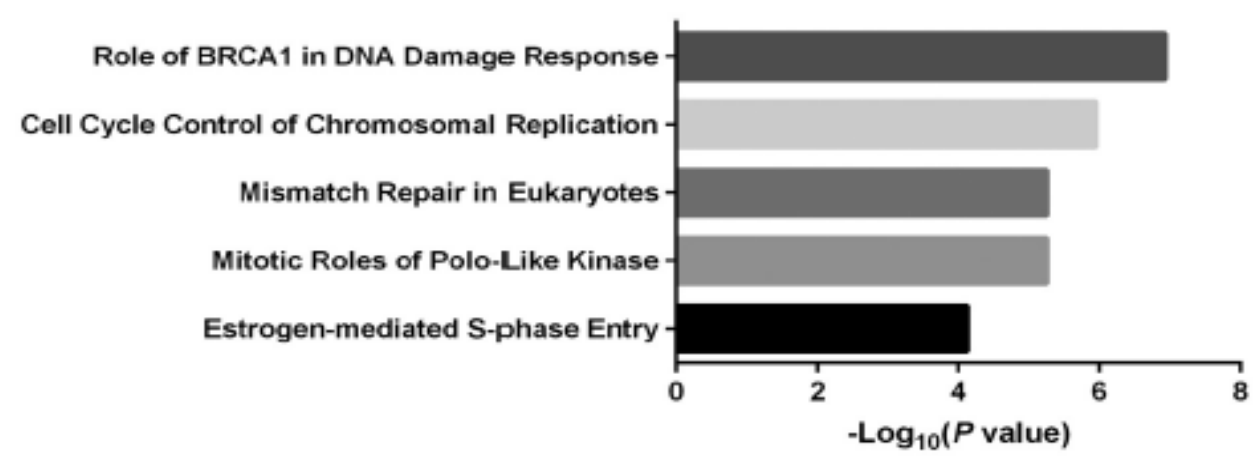

B

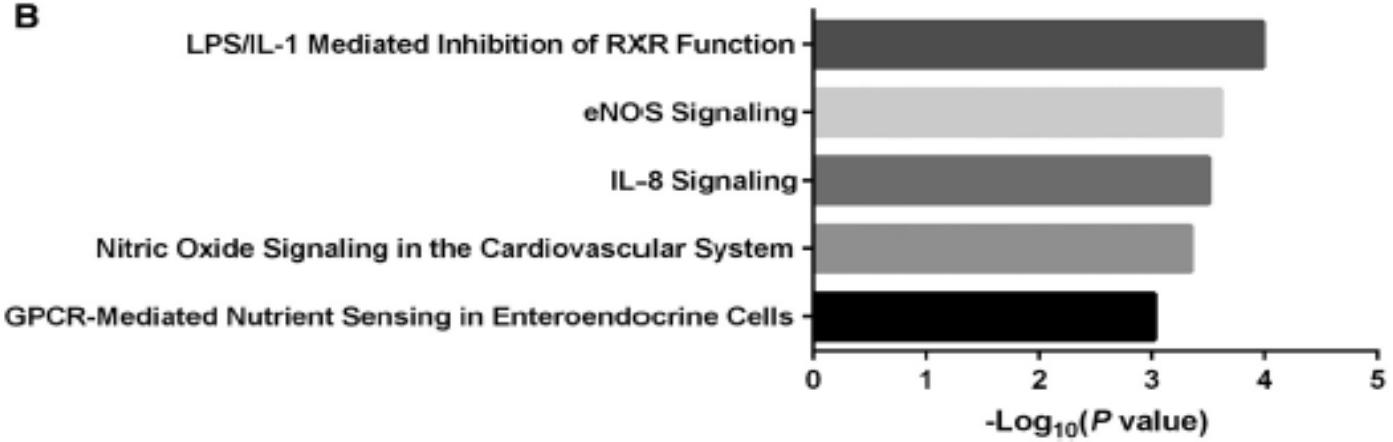

Figure 17: Ingenuity Pathway Analysis of genes of which high (A) and low (B) expression was associated with recurrence in papillary thyroid cancer

(Figure 17B). The top tox lists were "LPS/IL-1 Mediated Inhibition of RXR Function," "Cardiac Hypertrophy," "Xenobiotic Metabolism Signaling," "Increases Glomerular Injury," and "NRF2-mediated Oxidative Stress Response".

Initial TCGA global analysis proposed that the differentiation status of thyroid cancer can be determined by a set of genes involved in thyroid metabolism and function and were designated the Thyroid Differentiation Score (TDS) [168]. The TDS comprises expression data of 13 mRNAs and 3 miRNAs. Interestingly, we found that the expression of 7 TDS genes was in association with RFS (Figure 18). Low expression of these TDS genes was associated typically with a decrease in RFS. The only exception was PVRL4, high expression of which had a greater risk of recurrence. Low expression of TSHR, which encodes thyroid-stimulating hormone receptor, was also associated with a significantly less RFS. It has been shown that [160] the results of the remaining TDS genes. RFS was not associated with other genes participating in thyroid development, such as NKX2-1 (TTF1, logrank $\mathrm{P}=0.74)$, FOXE1 (TTF2, log-rank $\mathrm{P}=0.75)$, and PAX8 (log-rank $\mathrm{P}=0.19)$.

\section{Genomic global analysis of the TCGA}

Initial genomic global analysis of the TCGA of papillary thyroid cancer revealed that papillary thyroid cancers can be separated into 2 main groups, BRAFV600E-like and RAS-like [168]. The classifier design was based on the BRAFV600E-RAS score, which highly correlated with the TDS, although the 2 scores were derived independently and have no genes in common. BRAFV600E-like papillary cancers are enriched for the classic and tallcell histology, are less differentiated, and have an increased ERK output or overactivation of the mitogen-activated protein kinase (MAPK) pathway. Conversely, RAS-like cancers are characterized by follicular-variant histology, are associated with younger patients, and have a lesser expression of immune response genes. The 2 groups are fundamentally different at all genomic levels.

Using the ATA risk of recurrence as a surrogate outcome, the initial analysis found that the risk of recurrence was associated with mutation density and the TDS. The TDS only weakly correlated with tumor purity, indicating that the TDS was not influenced strongly by tumor stromal content or lymphocyte infiltration [168]. The analysis on real events during follow-up are in concordance with the results [160], showing that low expression of thyroid differentiation genes carried a greater risk of recurrence.

In a previous report, histopathologic characterization of radioactive iodine (RAI)-refractory disease suggested that dedifferentiation is not uncommon [175]. Dedifferentiation likely dampens the responses to RAI therapy. At present, patients with an RAI-refractory disease have limited alternative options for treatment and a decreased overall survival, partly because thyroid cancer is poorly responsive to cytotoxic chemotherapy [176].

Cancer is driven by changes in patterns of gene expression due to the accumulation of mutations or epigenetic modifications. The TCGA data support previous observations that RAI-refractory lesions have a greater frequency of BRAFV600E $[177,178]$. Mutations leading to constitutive activation of the MAPK signaling pathway inhibit the expression of proteins involved in the biosynthesis of thyroid hormones, including sodiumiodide symporter SLC5A5 (NIS) [179]. Of note, among the thyroid differentiation genes, it has been found that downregulation of NIS was the strongest predictor of a decreased RFS (Figure 18, logrank $\mathrm{P}=.0003$ ). Nuclear receptor 

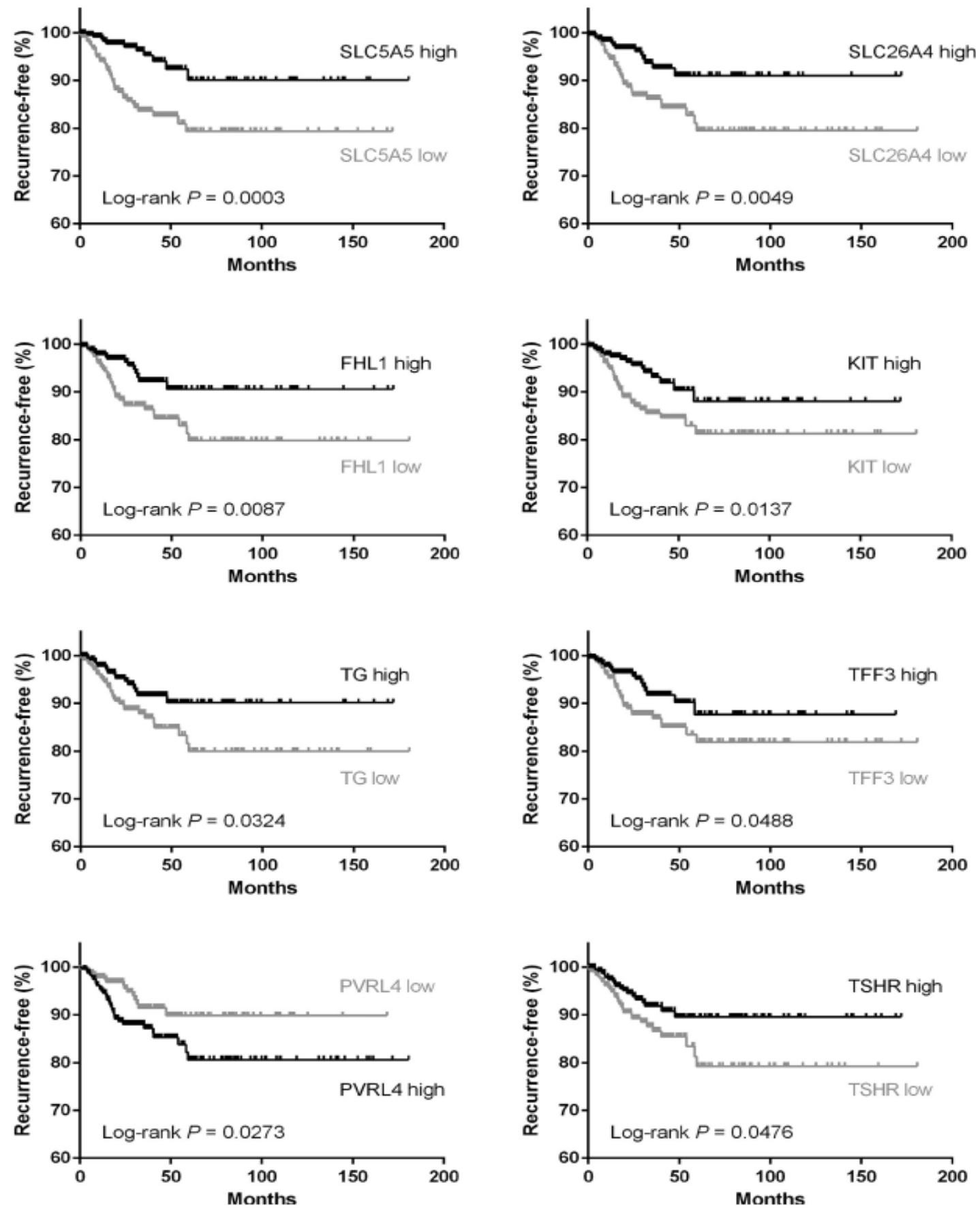

Figure 18: Kaplan-Meier recurrence-free survival of patients with papillary thyroid cancer $(n=504)$ dichotomized according to genes in association with thyroid differentiation. The sodium iodide symporter (NIS) is encoded by the solute carrier family 5 member 5 (SLC5A5).

ligands and epigenetic modifiers have been used to promote tumor redifferentiation, [180] while conventional redifferentiation agents, such as retinoic acid, had no clinically important benefits [181].

A plausible explanation is that pathways involving retinoic acid receptors and/or retinoid: $X$ receptors are also downregulated in these neoplasms. In these analyses, low expression of retinoic acid receptor beta (RARB) was associated with a significantly lesser RFS (log-rank $\mathrm{P}=.03$ ). Consistent with this observation, recent studies demonstrated that RARB expression was downregulated in papillary thyroid cancer and RARB silencing increased cell viability, decreased expression of NIS, and suppressed iodine uptake in thyroid cancer cells $[182,183]$. A more promising strategy may be targeting the MAPK signaling pathway. Accumulating evidence suggests that MAPK inhibition may provide better results in terms of iodine uptake and tumor response [184-186]. Further research is necessary to provide a more personalized approach, tailored to specific molecular alterations in individual patient tumors. 
A novel finding in the present study [160] is that high expression of cell cycle-regulating and DNA repair genes was associated with recurrence. Alterations in cell cycle-regulating genes promote transition through the cell cycle and ultimately drive tumor proliferation. Although prior studies suggest that Ki-67/MIB-1 stain positivity confers a greater risk of recurrence, [187] differentiated thyroid cancer has long been considered as a quiescent, chemotherapyresistant neoplasm. It is arguable whether modern drugs offer better effectiveness with fewer adverse events [188].

The findings [160] do not imply that cytotoxic agents possess high therapeutic potential in papillary thyroid cancer. Transcriptome analysis across 12 TCGA cancer types indicates that papillary thyroid cancer is poorly overlapped with other cancers in terms of differentially expressed genes [189]. Instead, it has been speculated that a proliferation signature may be used as a prognostic marker.

DNA repair machinery maintains a balance between genomic integrity and cell death. Previous work mainly focused on the association between polymorphisms of DNA repair genes and the risk of developing thyroid cancer [190]. Upregulation of DNA repair genes may render tumor cells less vulnerable to DNA damage and more resistant to treatment. It has been found that high expression of DNA repair genes was associated with an increased risk of recurrence. It may reflect genomic instability of more aggressive cancer; an alternative explanation is that tumors equipped with better repair capacity would more likely survive from RAI therapy.

The TCGA analysis showed that 2 significantly mutated genes related to DNA repair (PPM1D and CHEK2) occurred concomitantly with driver mutations in the MAPK pathway [168]. Interestingly, MAPK inhibition may result in radiosensitization by suppressing DNA repair pathways [191]. Combination or sequential treatments with RAI therapy and inhibition of the DNA-damage response may represent a new concept for the management of papillary thyroid cancer.

Limitations of this study [160] include the relatively short followup periods and not controlling for histologic variants or tumor stage of the papillary thyroid cancers studied. Additionally, in the present study, patients were divided into dichotomous groups for each gene analyzed. The underlying pathology is more likely to be "continuous" rather than categorical, and such groupings may not be meaningful biologically [192].

A recent analysis of the TCGA data by Stanford University used clinicopathologic characteristics to define good and poor prognosis [193]. The authors [160] reported individual potential targets and proposed a Prediction Analysis of Microarrays classifier. This study aimed at identifying recurrence-associated genes instead of developing a validated prognostic index. It has been hypothesized that using pathway analysis would provide a better mechanistic understanding of the biologic processes involved in tumor recurrence.

\section{Conclusions}

We discussed several siRNA delivery approaches focusing on their contributions to the control of $\mathrm{PK}$ and $\mathrm{BD}$ of siRNA. Solid tumors are obviously one of the most anticipated targets, and many studies show $\mathrm{PK} / \mathrm{BD}$ profiles favorable for siRNA delivery to tumors.
Despite the optimism prevalent in the literature, one may recognize that most clinical translations are made in the applications targeting the liver and the lung, where the majority of siRNA/NP systems naturally accumulate. This indicates that systemic delivery of siRNA in a therapeutic dose to tissues other than MPS organs remains suboptimal. Given the discrepancy, some of the current experimental practices may be worth reconsideration. First, many studies rely on labeling siRNA for PK and BD studies. As mentioned earlier, these approaches are valid only when the labeled components represent the full-length, bioactive siRNA; otherwise, inactive catabolites retaining the label may be mistaken for siRNA in target tissues. In addition, one should also consider that structural changes due to labeling might alter the PK/BD profiles of siRNA. To avoid overestimation of siRNA in $\mathrm{PK} / \mathrm{BD}$ studies, it is desirable to complement with hybridizationbased methods that can detect full-length siRNA, such as Northern blot analysis, hybridization-ligation assay, or PCR-based assay. Second, $\mathrm{BD}$ of siRNA is often presented as \% of injected dose per unit mass of tissue at the final time point of the study. While this presentation offers a useful means to compare the relative concentrations of siRNA in different tissues, it rarely reports the amount of siRNA collected in the feces and urine, making it difficult to judge the fraction of siRNA that was immediately excreted. A caveat of this practice is that relative siRNA distribution in selected tissues can mislead to an overrated optimism for target-specific siRNA delivery, when in reality the absolute amount of siRNA in target tissue may be only a small fraction of the injected dose. Such misinterpretation may be prevented by considering the concentration in each tissue in addition to the relative quantity. Finally, it is not unusual to see studies tracking carriers in lieu of siRNA in PK/BD studies. This approach may be valid when the siRNA/carrier complex remains stable throughout the study, which, however, should not be taken for granted without proof. It is possible that siRNA/carrier complexes disassemble prematurely during circulation but still show favorable pharmacological effects due to other biological events related to the carrier itself. In order to identify actual contribution of carriers to the siRNA delivery, it is desirable to track siRNA and carrier separately through distinct labeling and/or detection techniques.

In conclusion, we identified a set of recurrence-associated genes in papillary thyroid cancer. Pathway analyses indicate that upregulation of cell cycle-regulating genes and DNA repair genes and downregulation of thyroid differentiation genes carried a high risk of recurrence. Further research [194-197] will be required to determine whether pharmacologic measures that target these pathways improve clinical outcomes.

\section{References}

1. A Fire, S Xu, MK Montgomery, SA Kostas, SE Driver, CC Mello. Potent and specific genetic interference by double-stranded RNA in Caenorhabditis elegans, Nature. 1998; 391: 806-811.

2. SM Elbashir, J Harborth, W Lendeckel, A Yalcin, $\mathrm{K}$ Weber, T Tuschl. Duplexes of 21-nucleotide RNAs mediate RNA interference in cultured mammalian cells, Nature. 2001; 411: 494-498.

3. A Dose Escalation Trial of an Intravitreal Injection of Sirna-027 in Patients With Subfoveal Choroidal Neovascularization (CNV) Secondary to AgeRelated Macular Degeneration (AMD).

4. D Haussecker. Current issues of RNAi therapeutics delivery and development, J. Control. Release. 2014; 195: 49-54. 
5. S Seth, R Johns, MV Templin. Delivery and biodistribution of siRNA for cancer therapy: challenges and future prospects, Ther. Deliv. 2012; 3: 245 261.

6. R Kanasty, JR Dorkin, A Vegas, D Anderson. Delivery materials for siRNA therapeutics, Nat. Mater. 2013; 12: 967-977.

7. Study of ARC-520 in Patients with Chronic Hepatitis B Virus

8. A Guzman-Aranguez, P Loma, J Pintor. Small-interfering RNAs (siRNAs) as a promising tool for ocular therapy, Br. J. Pharmacol. 2013; 170: 730-747.

9. SJ Reich, J Fosnot, A Kuroki, W Tang, X Yang, AM Maguire, et al. Tolentino Small interfering RNA (siRNA) targeting VEGF effectively inhibits ocular neovascularization in a mouse model, Mol. Vis. 2003; 9: 210-216.

10. M Murata, T Takanami, S Shimizu, Y Kubota, S Horiuchi, W Habano, et al Inhibition of ocular angiogenesis by diced small interfering RNAs (siRNAs) specific to vascular endothelial growth factor (VEGF), Curr. Eye Res. 2006; 31: 171-180.

11. B Kim, Q Tang, PSBiswas, J Xu, RM Schiffelers, FY Xie. et al. Inhibition of ocular angiogenesis by siRNA targeting vascular endothelial growth factor pathway genes, Am. J. Pathol. 2004; 165: 2177-2185.

12. PK Kaiser, RC Symons, SM Shah, EJ Quinlan, H Tabandeh, DV Do, et al. Sirna-027 Study, RNAi-based treatment for neovascular age-related macular degeneration by Sirna-027, Am J. Ophthalmol. 2010; 150: 33-39 e32.

13. RN Frank, Diabetic retinopathy. N. Engl. J. Med. 2004; 350: 48-58.

14. AP Adamis, JW Miller, MT Bernal, DJ D'Amico, J Folkman, TK Yeo, et al. Increased vascular endothelial growth factor levels in the vitreous of eyes with proliferative diabetic retinopathy, Am J. Ophthalmol. 1994; 118: 445.450 .

15. AO Garba, SA Mousa. Bevasiranib for the treatment of wet, age-related macular degeneration, Ophthalmol. Eye Dis. 2010; 2: 75-83.

16. QD Nguyen, RA Schachar, CI Nduaka, M Sperling, AS Basile, KJ Klamerus, et al. Dose-ranging evaluation of intravitreal siRNA PF-04523655 for diabetic macular edema (the DEGAS study), Invest.Ophthalmol. Vis. Sci. 2012; 53 7666-7674

17. $\mathrm{H}$ Nakamura, SS Siddiqui, $X$ Shen, AB Malik, JS Pulido, NM Kumar, et al. RNA interference targeting transforming growth factor-beta type II receptor suppresses ocular inflammation and fibrosis, Mol. Vis. 2004; 10: 703-711.

18. H Ye, Y Qian, M Lin, Y Duan, X Sun, Y Zhuo, et al. Cationic nano-copolymers mediated IKKbeta targeting siRNA to modulate wound healing in a monkey model of glaucoma filtration surgery, Mol. Vis. 2010; 16: 2502-2510.

19. T Martinez, MV Gonzalez, I Roehl, N Wright, C Paneda, Al Jimenez. In vitro and in vivo efficacy of SYL040012, a novel siRNA compound for treatment of glaucoma, Mol. Ther. 2014; 22: 81-91.

20. A Thakur, S Fitzpatrick, A Zaman, K Kugathasan, B Muirhead, G Hortelano, et al. Strategies for ocular siRNA delivery: potential and limitations of nonviral nanocarriers, J. Biol. Eng. 2012; 6: 7.

21. A Rodriguez-Aguayo, A Chavez-Reyes, G Lopez-Berestein, AK Sood. RNA in cancer therapy, in: K Cheng, RI Mahato (Eds.), Advanced Delivery and Therapeutic Applications of RNAi, John Wiley and Sons, Ltd .2013; 271-307.

22. ME Davis, JE Zuckerman, CHJ Choi, D Seligson, A Tolcher, CA Alabi, et al. Evidence of RNAi in humans from systemically administered siRNA via targeted nanoparticles, Nature. 2010; 464: 1067-1070.

23. NS Gandhi, RK Tekade, MB Chougule. Nanocarrier mediated delivery of siRNA/miRNA in combination with chemotherapeutic agents for cancer therapy: current progress and advances, J. Control. Release. 2014; 194 238-256.

24. DR Senger, SJ Galli, AM Dvorak, CA Perruzzi, VS Harvey, HF Dvorak. Tumor cells secrete a vascular permeability factor that promotes accumulation of ascites fluid, Science. 1983; 219: 983-985.

25. MD Cole. The myc oncogene: its role in transformation and differentiation, Annu. Rev. Genet.1986; 20: 361-384.

26. EP Sulman, XX Tang, C Allen, JA Biegel, DE Pleasure, GM Brodeur, et al. ECK a human EPH-related gene, maps to $1 \mathrm{p} 36.1$, a common region of alteration in human cancers, Genomics. 1997; 40: 371-374

27. UR Rapp, MD Goldsborough, GE Mark, TI Bonner, J Groffen, FH Reynolds $\mathrm{Jr}$, et al. Structure and biological activity of v-raf, a unique oncogene transduced by a retrovirus, Proc. Natl. Acad. Sci. U. S. A. 1983; 80: 42184222.

28. U Holtrich, G Wolf, A Brauninger, T Karn, B Bohme, H RubsamenWaigmann, et al. Induction and down-regulation of PLK, a human serine/ threonine kinase expressed in proliferating cells and tumors, Proc. Natl. Acad. Sci. U. S. A. 1994; 91: 1736-1740.

29. MG Lee, $P$ Nurse. Complementation used to clone a human homologue of the fission yeast cell cycle control gene cdc2, Nature. 1987; 327: 31-35.

30. RL Juliano, V Ling. A surface glycoprotein modulating drug permeability in Chinese hamster ovary cell mutants, Biochim. Biophys. Acta. 1976; 455: 152-162.

31. Y Chen, H Gu, DS Zhang, F Li, T Liu, W Xia. Highly effective inhibition of lung cancer growth and metastasis by systemic delivery of siRNA via multimoda mesoporous silica-based nanocarrier, Biomaterials. 2014; 35: 10058-10069.

32. X Liu, W Wang, D Samarsky, L Liu, Q Xu, W Zhang, et al. Tumor-targeted in vivo gene silencing via systemic delivery of cRGD-conjugated siRNA, Nucleic Acids Res. 2015; 42: 11805-11817.

33. Y Chen, SR Bathula, Q Yang, L Huang. Targeted nanoparticles deliver siRNA to melanoma, J. Investig.Dermatol. 2010; 130: 2790-2798.

34. Y Chen, X Zhu, X Zhang, B Liu, L Huang. Nanoparticles modified with tumortargeting scFv deliver siRNA and miRNA for cancer therapy, Mol. Ther. 2010; 18: 1650-1656.

35. CN Landen Jr., A Chavez-Reyes, C Bucana, R Schmandt, MT Deavers, G Lopez-Berestein, et al. Therapeutic EphA2 gene targeting in vivo using neutral liposomal small interfering RNA delivery, Cancer Res. 2005; 65 6910-6918.

36. ST Chou, Q Leng, P Scaria, JD Kahn, LJ Tricoli, M Woodle, et al. Surfacemodified HK:siRNA nanoplexes with enhanced pharmacokinetics and tumor growth inhibition, Biomacromolecules. 2013; 14: 752-760.

37. Y Sakurai, H Hatakeyama, Y Sato, M Hyodo, H Akita, H Harashima. Gene silencing via RNAi and siRNA quantification in tumor tissue using MEND, a liposomal siRNA delivery system, Mol. Ther. 2013; 21: 1195-1203.

38. Y Liu, YH Zhu, CQ Mao, S Dou, S Shen, ZB Tan, et al. Triple negative breast cancer therapy with CDK1 siRNA delivered by cationic lipid assisted PEGPLA nanoparticles, J. Control. Release. 2014; 192: 114-121.

39. L Zhu, F Perche, T Wang, VP Torchilin. Matrix metalloproteinase 2-sensitive multifunctional polymeric micelles for tumor-specific co-delivery of siRNA and hydrophobic drugs, Biomaterials. 2014; 35: 4213-4222.

40. JY Yhee, S Song, SJ Lee, SG Park, KS Kim, MG Kim, Set al. Cancer-targeted MDR-1 siRNA delivery using self-cross-linked glycol chitosan nanoparticles to overcome drug resistance, J. Control. Release. 2015; 198: 1-9.

41. G Neufeld, T Cohen, S Gengrinovitch, Z Poltorak. Vascular endothelia growth factor (VEGF) and its receptors, FASEB J. 1999; 13: 9-22.

42. D Zhuang, S Mannava, V Grachtchouk, WH Tang, S Patil, JA Wawrzyniak et al. C-MYC overexpression is required for continuous suppression of oncogene-induced senescence in melanoma cells, Oncogene. 2008; 27 : $6623-6634$

43. RW Johnstone, AA Ruefli, SW Lowe. Apoptosis: a link between cancer genetics and chemotherapy, Cell. 2002; 108: 153-164.

44. PH Thaker, M Deavers, J Celestino, A Thornton, MS Fletcher, CN Landen, et al. Sood, EphA2 expression is associated with aggressive features in ovarian carcinoma, Clin. Cancer Res. 2004; 10: 5145-5150.

45. M Nakamoto, AD Bergemann. Diverse roles for the Eph family of recepto tyrosine kinases in carcinogenesis, Microsc. Res. Tech. 2002; 59: 58-67.

46. F Eckerdt, J Yuan, K Strebhardt. Polo-like kinases and oncogenesis, Oncogene. 2005; 24: 267-276. 
47. K Ando, T Ozaki, H Yamamoto, K Furuya, M Hosoda, S Hayashi, et al Polo-like kinase 1 (Plk1) inhibits p53 function by physical interaction and phosphorylation, J. Biol. Chem. 2004; 279: 25549-25561.

48. M Malumbres, M Barbacid. Mammalian cyclin-dependent kinases, Trends Biochem. Sci. 2005; 30: 630-641.

49. M Malumbres, M Barbacid. To cycle or not to cycle: a critical decision in cancer, Nat. Rev. Cancer. 2001; 1: 222-231.

50. M. Malumbres. Cyclin-dependent kinases,Genome Biol. 2014;15: 122.

51. P Bonelli, FM Tuccillo, A Borrelli, A Schiattarella, FM Buonaguro. CDK/ $\mathrm{CCN}$ and $\mathrm{CDKI}$ alterations for cancer prognosis and therapeutic predictivity, Biomed. Res. Int. 2014; 2014: 361020

52. Breakthrough Therapies.

53. G Ambrosini, C Adida, DC Altieri. A novel anti-apoptosis gene, survivin expressed in cancer and lymphoma, Nat. Med. 1997; 3: 917-921.

54. DC Altieri. Survivin, versatile modulation of cell division and apoptosis in cancer, Oncogene. 2003; 22: 8581-8589.

55. G Bradley, V Ling. P-glycoprotein, multidrug resistance and tumor progression, Cancer Metastasis Rev. 1994; 13: 223-233.

56. M Abbasi, A Lavasanifar, H Uludag. Recent attempts at RNAi-mediated Pglycoprotein downregulation for reversal of multidrug resistance in cancer Med. Res. Rev. 2013; 33: 33-53.

57. C Lorenzer, M Dirin, AM Winkler, V Baumann, J Winkler. Going beyond the liver: progress and challenges of targeted delivery of siRNA therapeutics, J. Control. Release. 2015; 203: 1-15.

58. P Arbuthnot, A Ely, MS Weinberg. Hepatic delivery of RNA interference activators for therapeutic application, Curr. Gene Ther. 2009; 9: 91-103.

59. A Erez, OA Shchelochkov, SE Plon, F Scaglia, B Lee. Insights into the pathogenesis and treatment of cancer from inborn errors of metabolism, Am J. Hum. Genet. 2011; 88: 402-421.

60. MRS Alix Scholer-Dahirel, Alice Loo, Linda Bagdasarian, Ronald Meyer Ribo Guo, Steve Woolfenden, et al. Maintenance of adenomatous polyposis coli (APC)-mutant colorectal cancer is dependent on Wnt/ $\beta$-catenin signaling, Proc. Natl. Acad. Sci. U. S. A. 2011; 108: 17135-17140.

61. E Raskopf, A Vogt, T Sauerbruch, V Schmitz. siRNA targeting VEGF inhibits hepatocellular carcinoma growth and tumor angiogenesis in vivo, J. Hepatol. 2008; 49: 977-984.

62. K Zhang, K Chu, X Wu, H Gao, J Wang, YC Yuan, et al. Amplification of FRS2 and activation of FGFR/FRS2 signaling pathway in high-grade liposarcoma, Cancer Res. 2013; 73: 1298-1307.

63. PG Rychahou, LN Jackson, SR Silva, S Rajaraman, BM Evers Targetedmolecular therapy of the PI3K pathway: therapeutic significance of PI3K subunit targeting in colorectal carcinoma, Ann. Surg. 2006; 243: 833 842.

64. H Clevers. Wnt/beta-catenin signaling in development and disease, Cell 2006; 127: 469-480

65. AO Kaseb, A Hanbali, M Cotant, MM Hassan, I Wollner, PA.Philip. Vascular endothelial growth factor in the management of hepatocellular carcinoma: a review of literature, Cancer. 2009; 115: 4895-4906.

66. VP Eswarakumar, I Lax, J Schlessinger. Cellular signaling by fibroblas growth factor receptors, Cytokine Growth Factor Rev. 2005; 16: 139-149.

67. DA Fruman C Rommel. PI3K and cancer: lessons, challenges and opportunities, Nat. Rev. Drug Discov. 2014; 13: 140-156.

68. P Huang, $X X$ X, L Wang, B Zhu, X Wang, J Xia. The role of EGFEGFR signaling pathway in hepatocellular carcinoma inflammatory microenvironment, J. Cell. Mol. Med. 2014; 18: 218-230.

69. S Whittaker, R Marais, AX Zhu. The role of signaling pathways in the development and treatment of hepatocellular carcinoma, Oncogene. 2010 29: 4989-5005.

70. G Szabo, S Bala. MicroRNAs in liver disease, Nat. Rev. Gastroenterol
Hepatol. 2013; 10: 542-552.

71. F Azam, A Koulaouzidis. Hepatitis B virus and hepatocarcinogenesis, Ann Hepatol. 2008; 7: 125-129.

72. AB Cefalu, JP Pirruccello, D Noto, S Gabriel, V Valenti, N Gupta, et al. A novel $A P O B$ mutation identified by exome sequencing cosegregates with steatosis, liver cancer, and hypocholesterolemia, Arterioscler.Thromb.Vasc. Biol. 2013; 33: 2021-2025.

73. XQ Wang, W Zhang, EL Lui, Y Zhu, P Lu, X Yu, et al. Notch-Snail-E-cadherin pathway in metastatic hepatocellular carcinoma, Int. J. Cancer. 2012; 131 E163-E172.

74. M Riaz, M Idrees, $\mathrm{H}$ Kanwal, F Kabir. An overview of triple infection with hepatitis B, C and D viruses, Virol. J. 2011; 8: 368

75. Hepatitis B information for public.

76. D Halegoua-De Marzio, HW Hann. Then and now: the progress in hepatitis B treatment over the past 20 years, World J. Gastroenterol. 2014; 20: 401-413.

77. CI Wooddell, DB Rozema, M Hossbach, M John, HL Hamilton, Q Chu, et al Hepatocyte-targeted RNAi therapeutics for the treatment of chronic hepatitis B virus infection, Mol. Ther. 2013; 21: 973-985.

78. S Carmona, MR Jorgensen, S Kolli, C Crowther, FH Salazar, PL Marion, et al. Controlling HBV replication in vivo by intravenous administration of triggered PEGylated siRNA-nanoparticles, Mol. Pharm. 2009; 6: 706-717.

79. SI Kim, D Shin, TH Choi, JC Lee, GJ Cheon, KY Kim, et al. Systemic and specific delivery of small interfering RNAs to the livermediated by apolipoprotein A-I, Mol. Ther. 2007; 15: 1145-1152.

80. M Konishi, $\mathrm{CH}$ Wu, GY Wu. Inhibition of HBV replication by siRNA in a stable HBV-producing cell line, Hepatology. 2003; 38: 842-850.

81. G Li, G Jiang, J Lu, S Chen, L Cui, J Jiao, et al. Inhibition of hepatitis B virus cccDNA by siRNA in transgenic mice, Cell Biochem. Biophys. 2014; 69: 649-654.

82. GQ Li, HX Gu, D Li, WZ Xu. Inhibition of hepatitis B virus cccDNA replication by siRNA, Biochem. Biophys. Res. Commun. 2007; 355: 404-408.

83. D Grimm. All for one, one for all: new combinatorial RNAi therapies combat hepatitis C virus evolution, Mol. Ther. 2012; 20: 1661-1663

84. TJ Liang, MG Ghany. Current and future therapies for hepatitis C virus infection, N. Engl. J. Med. 2013; 368: 1907-1917.

85. M Korf, D Jarczak, C Beger, MP Manns, M Kruger. Inhibition of hepatitis $C$ virus translation and subgenomic replication by siRNAs directed against highly conserved HCV sequence and cellular HCV cofactors, J. Hepatol. 2005; 43: 225-234.

86. T Watanabe, T Umehara, F Yasui, SI Nakagawa, J Yano, T Ohgi. et al. Liver target delivery of small interfering RNA to the HCV gene by lactosylated cationic liposome, J. Hepatol. 2007; 47: 744-750.

87. H Ma, A Dallas, H Ilves, J Shorenstein, I MacLachlan, K Klumpp, et al Formulated minimal-length synthetic small hairpin RNAs are potent inhibitors of hepatitis C virus in mice with humanized livers, Gastroenterology. 2014; 146: 63-66.e65.

88. PK Chandra, AK Kundu, S Hazari, S Chandra, L Bao, T Ooms, et al Inhibition of hepatitis $C$ virus replication by intracellular delivery of multiple siRNAs by nanosomes, Mol. Ther. 2012; 20: 1724-1736.

89. SI Kim, D Shin, H Lee, BY Ahn, Y Yoon, M Kim. Targeted delivery of siRNA against hepatitis $\mathrm{C}$ virus by apolipoprotein $\mathrm{A}-\mathrm{I}$-bound cationic liposomes, J. Hepatol. 2009; 50: 479-488.

90. M Ansar, UA Ashfaq, I Shahid, MT Sarwar, T Javed, S Rehman, et al Inhibition of full length hepatitis $C$ virus particles of 1a genotype through small interference RNA, Virol. J. 2011; 8: 203.

91. TW Geisbert, ACH Lee, M Robbins, JB Geisbert, AN Honko, V Sood, et al. Postexposure protection of non-human primates against a lethal Ebola virus challenge with RNA interference: a proof-of-concept study, Lancet. 2010; 375: 1896-1905. 
92. TW Geisbert, LE Hensley, E Kagan, EZ Yu, JB Geisbert, K DaddarioDiCaprio, et al. Postexposure protection of guinea pigs against a lethal ebola virus challenge is conferred by RNA interference, J. Infect. Dis. 2006; 193 1650-1657.

93. A Shlomai, Y Shaul. Inhibition of hepatitis B virus expression and replication by RNA interference, Hepatology. 2003; 37: 764-770.

94. OM Merkel, I Rubinstein, T Kissel. siRNA delivery to the lung: what's new? Adv. Drug Deliv. Rev. 2014; 75: 112-128.

95. C Kelly, AB Yadav, PJ McKiernan, CM Greene, SA Cryan. RNAi in respiratory diseases, in: K. Cheng, R.I. Mahato (Eds.), Advanced Delivery and Therapeutic Applications of RNAi, John Wiley and Sons, Ltd. 2013; 391 416.

96. M Grzelinski, O Pinkenburg, T Buch, M Gold, S Stohr, H Kalwa, et al. Critical role of $\mathrm{G}($ alpha)12 and $\mathrm{G}$ (alpha)13 for human small cell lung cancer cell proliferation in vitro and tumor growth in vivo, Clin. Cancer Res. 2010; 16 $1402-1415$

97. DE Zamora-Avila, P Zapata-Benavides, MA Franco-Molina, S SaavedraAlonso, LM Trejo-Avila, D Resendez-Perez, et al. WT1 gene silencing by aerosol delivery of PEI-RNAi complexes inhibits B16-F10 lung metastases growth, Cancer Gene Ther. 2009; 16: 892-899.

98. Q Ge, L Filip, A Bai, T Nguyen, HN Eisen, J Chen. Inhibition of influenza virus production in virus-infected mice by RNA interference, Proc. Natl. Acad. Sci. U. S. A. 2004; 101: 8676-8681.

99. M Thomas, JJ Lu, Q Ge, C Zhang, J Chen, AM Klibanov. Full deacylation of polyethylenimine dramatically boosts its gene delivery efficiency and specificity to mouse lung, Proc. Natl. Acad. Sci. U. S. A. 2005; 102: 5679 5684.

100.V Bitko, A Musiyenko, O Shulyayeva, S Barik. Inhibition of respiratory viruses by nasally administered siRNA, Nat. Med. 2005; 11: 50-55.

101.KL Clark, SA Hughes, P Bulsara, J Coates, K Moores, J Parry, et al. Pharmacological characterization of a novel ENaCalpha siRNA (GSK2225745) with potential for the treatment of cystic fibrosis, Mol. Ther.Nucleic Acids. 2013; 2: e65.

102.JH Seong, KM Lee, ST Kim, SE Jin, CK Kim. Polyethylenimine-based antisense oligodeoxynucleotides of IL-4 suppress the production of IL-4 in a murine model of airway inflammation, J. Gene. Med. 2006; 8: 314-323.

103. TN Lively, K Kossen, A Balhorn, T Koya, S Zinnen, K Takeda, et al. Effect of chemically modified IL-13 short interfering RNA on development of airway hyperresponsiveness in mice, J. Allergy Clin. Immunol. 2008; 121: 88-94.

104. M Zheng, D Librizzi, A Kilic, Y Liu, H Renz, OM Merkel, et al. Enhancing in vivo circulation and siRNA delivery with biodegradable polyethyleniminegraftpolycaprolactone-block-poly(ethylene glycol) copolymers, Biomaterials. 2012; 33: 6551-6558.

105. Y Oe, RJ Christie, M Naito, SA Low, S Fukushima, K Toh, et al. Activelytargeted polyion complex micelles stabilized by cholesterol and disulfide cross-linking for systemic delivery of siRNA to solid tumors, Biomaterials. 2014; 35: 7887-7895.

106. Y Matsumoto, T Nomoto, H Cabral, Y Matsumoto, S Watanabe, RJ Christie, et al. Direct and instantaneous observation of intravenously injected substances using intravital confocal micro-videography, Biomed. Opt. Express. 2010; 1: 1209-1216.

107.FM van de Water, OC Boerman, AC Wouterse, JG Peters, FG Russel, R Masereeuw. Intravenously administered short interfering RNA accumulates in the kidney and selectively suppresses gene function in renal proximal tubules, Drug Metab. Dispos. 2006; 34: 1393-1397.

108. J Christensen, K Litherland, T Faller, E van de Kerkhof, F Natt, J Hunziker, et al. Metabolism studies of unformulated internally [3H]-labeled short interfering RNAs in mice, Drug Metab.Dispos. 2013; 41: 1211-1219.

109.S Gao, F Dagnaes-Hansen, EJ Nielsen, J Wengel, F Besenbacher, KA Howard, et al. The effect of chemicalmodification and nanoparticle formulation on stability and biodistribution of siRNA in mice, Mol. Ther. 2009; 17: $1225-1233$
110. J Christensen, K Litherland, T Faller, E van de Kerkhof, F Natt, J Hunziker, et al. Biodistribution and metabolism studies of lipid nanoparticleformulated internally [3H]-labeled siRNA in mice, Drug Metab. Dispos. 2014; 42: 431440.

111. G Ozcan, B Ozpolat, RL Coleman, AK Sood, G Lopez-Berestein. Preclinica and clinical development of siRNA-based therapeutics, Adv. Drug Deliv. Rev. 2015; 87: 108-119.

112. J Tabernero, GI Shapiro, PM LoRusso, A Cervantes, GK Schwartz, GJ Weiss, et al. First-in-humans trial of an RNA interference therapeutic targeting VEGF and KSP in cancer patients with liver involvement, Cancer Discov. 2013; 3: 406.417.

113. B Schultheis, D Strumberg, A Santel, C Vank, F Gebhardt, O Keil, et al. First-in-human phase I study of the liposomal RNA interference therapeutic Atu027 in patients with advanced solid tumors, J. Clin. Oncol. 2014; 32: 4141-4148.

114. DW Bartlett, H Su, IJ Hildebrandt, WA Weber, ME Davis. Impact of tumorspecific targeting on the biodistribution and efficacy of siRNA nanoparticles measured by multimodality in vivo imaging, Proc. Natl. Acad. Sci. U. S. A. 2007; 104: 15549-15554.

115. JE Zuckerman, I Gritli, A Tolcher, JD Heidel, D Lim, R Morgan, et al. Correlating animal and human phase la/lb clinical data with CALAA-01, a targeted, polymer-based nanoparticle containing siRNA, Proc. Natl. Acad. Sci. U. S. A. 2014; 111: 11449-11454

116. RZ Yu, B Baker, A Chappell, RS Geary, E Cheung, AA Levin. Development of an ultrasensitive noncompetitive hybridization-ligation enzymelinked immunosorbent assay for the determination of phosphorothioate oligodeoxynucleotide in plasma, Anal.Biochem. 2002; 304: 19-25.

117. JE Zuckerman, CH Choi, H Han, ME Davis. Polycation-siRNA nanoparticles can disassemble at the kidney glomerular basement membrane, Proc. Natl. Acad. Sci. U. S. A. 2012; 109: 3137-3142.

118. Y. Chen, J.J. Wu, L. Huang, Nanoparticles targeted with NGR motif delive c-myc siRNA and doxorubicin for anticancer therapy, Mol. Ther. 2010; 18: 828-834.

119. MS Lee, JE Lee, E Byun, NW Kim, K Lee, H Lee, et al. Target-specific delivery of siRNA by stabilized calcium phosphate nanoparticles using dopahyaluronic acid conjugate, J. Control. Release. 2014; 192: 122-130.

120. F Pittella, H Cabral, Y Maeda, P Mi, S Watanabe, H Takemoto, et al. Systemic siRNA delivery to a spontaneous pancreatic tumor model in transgenic mice by PEGylated calcium phosphate hybrid micelles, J. Control. Release. 2014; 178: $18-24$.

121.S Son, S Song, SJ Lee, S Min, SA Kim, JY Yhee, et al. Self-crosslinked human serum albumin nanocarriers for systemic delivery of polymerized siRNA to tumors, Biomaterials. 2013; 34: 9475-9485.

122. B Shi, E Keough, A Matter, K Leander, S Young, E Carlini, et al. Biodistribution of small interfering RNA at the organ and cellular levels after lipid nanoparticle-mediated delivery, J. Histochem.Cytochem. 2011; 59: 727740.

123. KY Choi, OF Silvestre, X Huang, KH Min, GP Howard, N Hida, et al. Versatile RNA interference nanoplatform for systemic delivery of RNAs, ACS Nano. 2014; 8: 4559-4570.

124. SA Jensen, ES Day, CH Ko, LA Hurley, JP Luciano, FM Kouri, et al Spherical nucleic acid nanoparticle conjugates as an RNAi-based therapy for glioblastoma, Sci. Transl. Med. 2013; 5: 209-152.

125. A Schlegel, C Largeau, P Bigey, M Bessodes, K Lebozec, D Scherman, et al. Anionic polymers for decreased toxicity and enhanced in vivo delivery of siRNA complexed with cationic liposomes, J. Control. Release. 2011; 152 393-401.

126. J Gao, H Chen, Y Yu, J Song, H Song, X Su, et al. Inhibition of hepatocellular carcinoma growth using immunoliposomes for co-delivery of adriamycin and ribonucleotide reductaseM2 siRNA, Biomaterials. 2013; 34: 10084-10098.

127. XB Xiong, A Lavasanifar. Traceable multifunctional micellar nanocarriers for cancer-targeted co-delivery of MDR-1 siRNA and doxorubicin, ACS Nano. 


\section{1: 5: 5202-5213.}

128. G Sass, P Leukel, V Schmitz, E Raskopf, M Ocker, D Neureiter, et al Inhibition of heme oxygenase 1 expression by small interfering RNA decreases orthotopic tumor growth in livers of mice, Int. J. Cancer. 2008; 123: $1269-1277$

129. Jinho Park, Joonyoung Park, Yihua Pei, Jun Xu, Yoon Yeo. Pharmacokinetics and biodistribution of recently-developed siRNA nanomedicines. Advanced Drug Delivery Reviews. 2016; 104: 93-109.

130.M Kornek, V Lukacs-Kornek, A Limmer, E Raskopf, U Becker, M Klockner, et al. 1,2-Dioleoyl-3-trimethylammonium-propane (DOTAP)formulated, immune-stimulatory vascular endothelial growth factor a smal interfering RNA (siRNA) increases antitumoral efficacy inmurine orthotopic hepatocellular carcinoma with liver fibrosis, Mol. Med. 2008; 14: 365-373.

131. L Li, R Wang, D Wilcox, A Sarthy, X Lin, X Huang, et al. Developing lipid nanoparticle-based siRNA therapeutics for hepatocellular carcinoma using an integrated approach, Mol. Cancer Ther. 2013; 12: 2308-2318.

132. J Gao, Y Yu, Y Zhang, J Song, H Chen, W Li, et al. EGFR-specific PEGylated immunoliposomes for active siRNA delivery in hepatocellular carcinoma Biomaterials. 2012; 33: 270-282.

133. DV Morrissey, JA Lockridge, L Shaw, K Blanchard, K Jensen, W Breen, et al Potent and persistent in vivo anti-HBV activity of chemicallymodified siRNAs, Nat. Biotechnol. 2005; 23: 1002-1007.

134.DV Morrissey, K Blanchard, L Shaw, K Jensen, JA Lockridge, B Dickinson, et al. Activity of stabilized short interfering RNA in a mouse model of hepatitis B virus replication, Hepatology. 2005; 41: 1349-1356.

135. M Mével, N Kamaly, S Carmona, MH Oliver, MR Jorgensen, C Crowther, et al. DODAG; a versatile new cationic lipid that mediates efficient delivery of pDNA and siRNA, J. Control. Release. 2010; 143: 222-232.

136. H Lee, SI Kim, D Shin, Y Yoon, TH Choi, GJ Cheon, et al. Hepatic siRNA delivery using recombinant human apolipoprotein A-I in mice, Biochem. Biophys. Res. Commun. 2009; 378: 192-196.

137. Study of ARC-520 in Patients with Chronic Hepatitis B Virus.

138. Safety, Tolerability and Pharmacokinetic First in Human (FIH) Study for Intravenous (IV) TKM-100802

139. CS Kraft, AL Hewlett, S Koepsell, AM Winkler, CJ Kratochvil, L Larson, et al. The use of TKM-100802 and convalescent plasma in 2 patients with Ebola virus disease in the United States, Clin.Infect. Dis. 2015; 61: 496-502.

140.M Gunther, J Lipka, A Malek, D Gutsch, W Kreyling, A Aigner. Polyethylenimines for RNAi-mediated gene targeting in vivo and siRNA delivery to the lung, Eur. J. Pharm. Biopharm. 2011; 77: 438-449.

141. ME Bonnet, JB Gossart, E Benoit, M Messmer, O Zounib, V Moreau, et al Systemic delivery of sticky siRNAs targeting the cell cycle for lung tumor metastasis inhibition, J. Control. Release. 2013; 170: 183-190.

142. AL Bolcato-Bellemin, ME Bonnet, G Creusat, P Erbacher, JP Behr. Sticky overhangs enhance siRNA-mediated gene silencing, Proc. Natl. Acad. Sci. U. S. A. 2007; 104: 16050-16055.

143.J McCaskill, R Singhania, M Burgess, R Allavena, S Wu, A Blumenthal, et al. Efficient biodistribution and gene silencing in the lung epithelium via intravenous liposomal delivery of siRNA, Mol. Ther. Nucleic Acids. 2013 2: e96.

144.V Fehring, U Schaeper, K Ahrens, A Santel, O Keil, M Eisermann, et al Delivery of therapeutic siRNA to the lung endothelium via novel lipoplex formulation DACC, Mol. Ther. 2014; 22: 811-820.

145. KJ Polach, M Matar, J Rice, G Slobodkin, J Sparks, R Congo, et al. Delivery of siRNA to the mouse lung via a functionalized lipopolyamine, Mol. Ther. 2012; 20: 91-100.

146. JE Dahlman, C Barnes, OF Khan, A Thiriot, S Jhunjunwala, TE Shaw, et al. In vivo endothelial siRNA delivery using polymeric nanoparticles with low molecular weight, Nat. Nanotechnol. 2014; 9: 648-655.

147. OB Garbuzenko, M Saad, S Betigeri, M Zhang, AA Vetcher, VA Soldatenkov et al. Intratracheal versus intravenous liposomal delivery of siRNA, antisense oligonucleotides and anticancer drug, Pharm. Res. 2009; 26: 382-394.

148. OM Merkel, A Beyerle, D Librizzi, A Pfestroff, TM Behr, B Sproat, et al. Nonviral siRNA delivery to the lung: investigation of PEG-PEI polyplexes and their in vivo performance, Mol. Pharm. 2009; 6: 1246-1260

149. B Gutbier, SM Kube, K Reppe, A Santel, C Lange, J Kaufmann, et al. RNAimediated suppression of constitutive pulmonary gene expression by small interfering RNA in mice, Pulm. Pharmacol.Ther. 2010; 23: 334-344.

150. A Wittrup, J Lieberman. Knocking down disease: a progress report on siRNA therapeutics, Nat. Rev. Genet. 2015; 16: 543-552.

151. AL Jackson, J Burchard, D Leake, A Reynolds, J Schelter, J Guo, et al Positionspecific chemicalmodification of siRNAs reduces "off-target" transcript silencing, RNA. 2006; 12: 1197-1205.

152. L Huang, J Jin, P Deighan, E Kiner, L McReynolds, J Lieberman. Efficient and specific gene knockdown by small interfering RNAs produced in bacteria, Nat. Biotechnol. 2013; 31: 350-356.

153.S Loisel, C Le Gall, L Doucet, C Ferec, V Floch. Contribution of plasmid DNA to hepatotoxicity after systemic administration of lipoplexes, Hum. Gene Ther. 2001; 12: 685-696.

154. JD Tousignant, AL Gates, LA Ingram, CL Johnson, JB Nietupski, SH Cheng et al. Comprehensive analysis of the acute toxicities induced by systemic administration of cationic lipid:plasmid DNA complexes in mice, Hum. Gene Ther. 2000; 11: 2493-2513.

155.W Yan, W Chen, L Huang. Mechanism of adjuvant activity of cationic liposome: phosphorylation of a MAP kinase, ERK and induction of chemokines, Mol. Immunol. 2007; 44: 3672-3681.

156.DP Vangasseri, Z Cui, W Chen, DA Hokey, LD Falo Jr., L Huang. Immunostimulation of dendritic cells by cationic liposomes, Mol. Membr. Biol. 2006; 23: 385-395.

157. T Tanaka, A Legat, E Adam, J Steuve, JS Gatot, M Vandenbranden, L. et al. DiC14-amidine cationic liposomes stimulate myeloid dendritic cells through Toll-like receptor 4, Eur. J. Immunol. 2008; 38: 1351-1357.

158. D Fischer, T Bieber, Y Li, HP Elsässer, T Kissel. A novel non-viral vector for DNA delivery based on low molecular weight, branched polyethylenimine: effect of molecular weight on transfection efficiency and cytotoxicity, Pharm. Res. 1999; 16: 1273-1279.

159. MA Islam, TE Park, B Singh, S Maharjan, J Firdous, MH Cho, et al. Major degradable polycations as carriers for DNA and siRNA, J. Control. Release. 2014; 193: 74-89.

160. Ming-Nan Chien, Po-Sheng Yang, Jie-Jen Lee, Tao-Yeuan Wang, YiChiung Hsu, Shih-Ping Cheng. Recurrence-associated genes in papillary thyroid cancer: An analysis of data from The Cancer Genome Atlas. Surgery. 2017: 161: 1642-1650.

161. Mao Y, Xing M. Recent incidences and differential trends of thyroid cancer in the USA. Endocr Relat Cancer. 2016; 23: 313-322.

162. Grogan RH, Kaplan SP, Cao H, Weiss RE, Degroot LJ, Simon CA, et al. A study of recurrence and death from papillary thyroid cancer with 27 years of median follow-up. Surgery. 2013; 154:1436-1446.

163. American Thyroid Association (ATA) Guidelines Taskforce on Thyroid Nodules and Differentiated Thyroid Cancer, Cooper DS, Doherty GM, Haugen BR, Kloos RT, Lee SL, Mandel SJ, et al. Revised American Thyroid Association management guidelines for patients with thyroid nodules and differentiated thyroid cancer. Thyroid. 2009; 19: 1167-1214

164. Haugen BR, Alexander EK, Bible KC, Doherty GM, Mandel SJ, Nikiforov YE, et al. 2015 American Thyroid Association management guidelines for adult patients with thyroid nodules and differentiated thyroid cancer: the American Thyroid Association guidelines task force on thyroid nodules and differentiated thyroid cancer. Thyroid. 2016; 26:1-133.

165. Cheng SP, Hsu YC, Liu CL, Liu TP, Chien MN, Wang TY, et al. Significance of allelic percentage of BRAF c.1799T > A (V600E) mutation in papillary thyroid carcinoma. Ann Surg Oncol. 2014; 21: S619-626. 
166. Gandolfi G, Sancisi V, Piana S, Ciarrocchi A. Time to reconsider the meaning of BRAF V600E mutation in papillary thyroid carcinoma. Int J Cancer. 2015 137:1001-1011.

167. Liu R, Xing M. TERT promoter mutations in thyroid cancer. Endocr Relat Cancer. 2016; 23: R143-155

168. Cancer Genome Atlas Research Network. Integrated genomic characterization of papillary thyroid carcinoma. Cell. 2014; 159: 676-690.

169. Wang J, Duncan D, Shi Z, Zhang B. WEB-based GEne SeT AnaLysis Toolkit (WebGestalt): update 2013. Nucleic Acids Res. 2013; 41: W77-83.

170. Huang da W, Sherman BT, Lempicki RA. Systematic and integrative analysis of large gene lists using DAVID bioinformatics resources. Nat Protoc. 2009; 4: 44-57.

171. Chang YC, Hsu YC, Liu CL, Huang SY, Hu MC, Cheng SP. Local anesthetics induce apoptosis in human thyroid cancer cells through the mitogenactivated protein kinase pathway. PLoS One. 2014; 9: e89563.

172. Kanehisa M, Sato Y, Kawashima M, Furumichi M, Tanabe M. KEGG as a reference resource for gene and protein annotation. Nucleic Acids Res. 2016; 44: D457-462

173. Lee F, Lee JJ, Jan WC, Wu CJ, Chen HH, Cheng SP. Molecular pathways associated with transcriptional alterations in hyperparathyroidism. Oncol Lett. 2016; 12: 621-626.

174. Chai YJ, Yi JW, Jee HG, Kim YA, Kim JH, Xing M, et al. Significance of the BRAF mRNA expression level in papillary thyroid carcinoma: an analysis of The Cancer Genome Atlas data. PLoS One. 2016; 11: e0159235.

175. Rivera M, Ghossein RA, Schoder H, Gomez D, Larson SM, Tuttle RM. Histopathologic characterization of radioactive iodine-refractory fluorodeoxyglucose-positron emission tomography-positive thyroid carcinoma. Cancer 2008; 113: 48-56.

176. Viola D, Valerio L, Molinaro E, Agate L, Bottici V, Biagini A, et al. Treatment of advanced thyroid cancer with targeted therapies: ten years of experience. Endocr Relat Cancer. 2016; 23: R185-205.

177. Mian C, Barollo S, Pennelli G, Pavan N, Rugge M, Pelizzo MR, et al. Molecular characteristics in papillary thyroid cancers (PTCs) with no 131 uptake. Clin Endocrinol (Oxf) 2008; 68: 108-116.

178. Sabra MM, Dominguez JM, Grewal RK, Larson SM, Ghossein RA, Tuttle $\mathrm{RM}$, et al. Clinical outcomes and molecular profile of differentiated thyroid cancers with radioiodine-avid distant metastases. J Clin Endocrinol Metab. 2013; 98: E829-836.

179. Portulano C, Paroder-Belenitsky M, Carrasco N. The Na+/lsymporter (NIS) mechanism and medical impact. Endocr Rev. 2014; 35: 106-149.

180.Spitzweg C, Bible KC, Hofbauer LC, Morris JC. Advanced radioiodinerefractory differentiated thyroid cancer: the sodium iodide symporter and other emerging therapeutic targets. Lancet Diabetes Endocrinol 2014; 2: 830-842.

181. Handkiewicz-Junak D, Roskosz J, Hasse-Lazar K, Szpak- Ulczok S Puch Z, Kukulska A, et al. 13-cis-retinoic acid redifferentiation therapy and recombinant human thyrotropin-aided radioiodine treatment of nonFunctional metastatic thyroid cancer: a single-center, 53-patient phase 2 study. Thyroid Res 2009; 2: 8.

182. Czajka AA, Wojcicka A, Kubiak A, Kotlarek M, Bakula-Zalewska E, Kopersk $\mathrm{L}$, et al. Family of microRNA-146 regulates RARb in papillary thyroid carcinoma. PLoS One. 2016; 11: e0151968.
183. Shen CT, Qiu ZL, Song HJ, Wei WJ, Luo QY. miRNA-106a directly targeting RARB associates with the expression of $\mathrm{Na}(+) / /(-)$ symporter in thyroid cancer by regulating MAPK signaling pathway. J Exp Clin Cancer Res 2016 35: 101

184. Ho AL, Grewal RK, Leboeuf R, Sherman EJ, Pfister DG, Deandreis D, et al. Selumetinib-enhanced radioiodine uptake in advanced thyroid cancer. N Engl J Med. 2013; 368: 623-32.

185. Rothenberg SM, McFadden DG, Palmer EL, Daniels GH, Wirth LJ. Redifferentiation of iodine-refractory BRAF V600E-mutant metastatic papillary thyroid cancer with dabrafenib. Clin Cancer Res. 2015; 21: 10281035

186. Brose MS, Cabanillas ME, Cohen EE, Wirth LJ, Riehl T, Yue H, et al. Vemurafenib in patients with BRAF(V600E)-positive metastatic or unresectable papillary thyroid cancer refractory to radioactive iodine: a nonrandomised, multicentre, open-label, phase 2 trial. Lancet Oncol. 2016; 17 : 1272-1282.

187. Ranjbari N, Rahim F. The Ki-67/MIB-1 index level and recurrence of papillary thyroid carcinoma. Med Hypotheses 2013; 80: 311-314.

188. Albero A, Lopez JE, Torres A, de la Cruz L, Martin T. Effectiveness of chemotherapy in advanced differentiated thyroid cancer: a systematic review. Endocr Relat Cancer. 2016; 23: R71-84.

189. Peng L, Bian XW, Li DK, Xu C, Wang GM, Xia QY, et al. Large-scale RNAseq transcriptome analysis of 4043 cancers and 548 normal tissue controls across 12 TCGA cancer types. Sci Rep. 2015; 5: 13413

190. Gatzidou E, Michailidi C, Tseleni-Balafouta S, Theocharis S. An epitome of DNA repair related genes and mechanisms in thyroid carcinoma. Cancer Lett. 2010; 290: 139-147.

191. Estrada-Bernal A, Chatterjee M, Haque SJ, Yang L, Morgan MA, Kotian S, et al. MEK inhibitor GSK1120212-mediated radiosensitization of pancreatic cancer cells involves inhibition of DNA double-strand break repair pathways. Cell Cycle. 2015; 14: 3713-3724.

192. Bovelstad HM, Nygard S, Storvold HL, Aldrin M, Borgan O, Frigessi A, et al. Predicting survival from microarray data-a comparative study. Bioinformatics 2007; 23: 2080-2087.

193. Brennan K, Holsinger C, Dosiou C, Sunwoo JB, Akatsu H, Haile R, et al. Development of prognostic signatures for intermediate-risk papillary thyroid cancer. BMC Cancer. 2016; 16: 736.

194. Loutfy H. Madkour Book: Reactive Oxygen Species (ROS), Nanoparticles, and Endoplasmic Reticulum (ER) Stress-Induced Cell Death Mechanisms. Paperback ISBN: 9780128224816 Imprint: Academic Press Published. 2020

195. Loutfy H. Madkour Book: Nanoparticles Induce Oxidative and Endoplasmic Reticulum Antioxidant Therapeutic Defenses.

196. Loutfy H. Madkour Book: Nucleic Acids as Gene Anticancer Drug Delivery Therapy. 1st Edition .Publishing house: Elsevier. 2020

197. Loutfy H. Madkour Book: Nanoelectronic Materials: Fundamentals and Applications (Advanced Structured Materials) 1st ed. 2019 